Orthotropic deck; Pure torsion test

\section{1. Introduction \\ 1. Introduction}

\title{
Experimental and numerical study of the torsional response of a modular hybrid FRP-aluminum triangular deck-truss beam
}

\author{
Dongdong Zhang ${ }^{\mathrm{a}}$, Qilin Zhao ${ }^{\mathrm{b}}$, Feng $\mathrm{Li}^{\mathrm{a}}{ }^{\text {** }}$, Yaxin Huang ${ }^{\mathrm{a}}$ \\ ${ }^{a}$ College of Field Engineering, PLA University of Science and Technology, Nanjing 210007, China \\ ${ }^{\mathrm{b}}$ College of Mechanical and Power Engineering, Nanjing University of Technology, Nanjing, 210009, China \\ *Corresponding author. Tel.: +86 13951627402; E-mail address: 83812546@qq.com (Feng Li)
}

\begin{abstract}
A hybrid fiber-reinforced polymer (FRP) - aluminum modular space truss emergency bridge has
\end{abstract} been designed that consists of two triangular deck-truss beams incorporating a new structural form and advanced pultruded FRP profiles. As a fundamental investigation, this paper explores the detailed torsional behaviors of the new triangular deck-truss beam. A full-scale specimen was prepared and tested under pure torsion to evaluate the representative structural performances. A three-dimensional finite element model (FEM) was constructed and validated with experimental results showing good comparisons. Furthermore, the torsional behavior of the triangular deck-truss beam was numerically investigated by removing individual primary truss members to clearly understand the torsional mechanism. It was found that the beam exhibited a specific and unfavorable mechanical behavior prohibiting full utilization of the FRP material' potential. The external torsional moment is primarily resisted by the torsion of the longitudinal profiles and the in-plane bending of the bilateral Vierendeel trusses rather than the out-of-plane bending of the web diagonals. Possible improvement and optimization procedures are further suggested for this beam when solely used as a structure subjected to off-axis load or pure torsion.

Keywords: Emergency bridge; Modular structure; Dismountable truss; Hybrid structure; Pultruded FRP profiles;

The availability and effectiveness of rapid emergency bridging systems are critical for the survival of military 
23 personnel and those affected by natural disasters. In response to the continued desire for emergency bridges with

24 lightweight, high strength, modular feasibility and fast construction, the applications of advanced materials, novel

25 structural form and new technique are preferred approaches. Pultruded fiber-reinforced polymer (FRP) materials

26 are increasingly used in the field of civil engineering as a result of their excellent properties, such as high

27 stiffness/strength-to-weight ratio, sufficient durability and shorter installation time [1-5]. In particular, these

28 features are ideal for new bridge constructions, such as bridge decks [6,7], footbridges [8,9], vehicular bridges

$29[10,11]$ and emergency bridges $[12,13]$. If the pultruded FRP profiles are further implemented in favorable

30 structural forms, e.g., planar [14,15], triangular [16,17], rectangular [18], spatial [19] and latticed trusses [20,21],

31 the advantages of both the materials and the structures will be greatly extended [22-25]. Finally, further weight

32 reduction and initial cost effectiveness could be achieved.

33 For the design of dismountable truss bridges assembled from pultruded FRP profiles, a key technique is to

34 conceive and design appropriate connections that can exploit the advantages of high stiffness and strength [22]. To

35 date, the usual jointing techniques for pultruded FRP profiles are bolted and bonded connections [26-28]. However,

36 the load-bearing capacity of these basic techniques is low and they are mainly applied to planar panels rather than

37 tubular member profile [29]. In response to this issue, several new jointing techniques were developed [22-23,30]

38 to address the inappropriate joint designs, which contribute much to the application of FRP materials in

39 heavy-traffic bridges [22-23,30]. A novel jointing technique termed the pre-tightened teeth connection (PTTC) was

40 proposed [31]. This PTTC technique enables the pultruded FRP profiles to exhibit superior mechanical

41 performance and to be easily connected with other structural members using conventional mechanical methods or

42 welding technology.

43 Based on the PTTC, a new hybrid FRP-aluminum space truss emergency bridge was designed [31]. The bridge 
44 has an ability to carry a traffic load weighing $100 \mathrm{kN}$ despite weighing only approximately 1.2 tons. The bridge

45 consists of twin trackways linked by hinged transverse braces. Each trackway is designed as a type of inverted

46 triangular deck-truss beam incorporating a new structural form and advanced pultruded FRP profiles, and is

47 composed of four modules jointed by male jugs and female jaws. An on-axis four-point bending loading test was

48 previously performed on a full-scale triangular deck-truss beam to examine the flexural behavior of the entire

49 bridge [31]. The results confirmed the feasibility of the PTTC technique and the favorable flexural properties of the

50 proposed bridge. In fact, for this type of bridge with the structural form of a spatial truss, the torsion caused by the

51 off-axis traffic load is usually a more critical loading condition controlling the structural responses than the on-axis

52 load. However, there are no reports of the detailed torsional behaviors of such a complete bridge.

53 Actually, when each triangular deck-truss beam is treated as a longitudinal girder, this twin-trackway bridge can

54 be regarded as a girder bridge composed of two longitudinal girders linked by rigid cross-beams. In this case, the

55 torsional behavior of such an equivalent twin-girder bridge can be analyzed according to the modified eccentric

56 compression method of the multi-girder bridges [32]. That is, the torsion of such a complete bridge can be

57 decomposed into bending and torsion of its twin triangular beams [33]. Thus, an understanding of the detailed

58 torsional response of the triangular deck-truss beam is fundamental to investigating the torsional behaviors of the

59 entire space truss bridge. However, such a study on the triangular deck-truss beam under torsion has not yet been

60 conducted. As a new structure, the hybrid triangular deck-truss beam is quite different in its structural configuration

61 from conventional steel triangular tubular trusses [34-36]. It is expected, therefore, that the hybrid triangular

62 deck-truss beam will exhibit unique torsional response, the investigation if which is necessary and meaningful.

63 The torsional response of the new bridge is characterized using a research program with the following two-part

64 scope: (i) an experimental and numerical study on a triangular deck-truss beam; and (ii) an experimental and 
65 numerical study on a complete space truss structure. The present paper focuses on stage (i), whereas stage (ii) will

66 be addressed in forthcoming papers. In this paper, two full-scale triangular modules are mounted to a specimen and

67 investigated through pure torsional testing and numerical analysis. The representative structural response are

68 studied in detail. Furthermore, to clearly understand the roles of different trussed members in the torsional

69 mechanism, a corresponding numerical analysis is conducted by removing different primary truss members.

70 Subsequently, possible structural improvements and optimization steps for the structure in question are discussed

71 for cases when the triangular deck-truss beam is solely used as a structure subjected to an off-axis load and torsion.

\section{2. Description of the structure}

The hybrid triangular deck-truss beam of the proposed emergency bridge [31] is mounted using four modules

composed of an aluminum orthotropic deck supported by aluminum and pultruded FRP profiles. The orthotropic

deck is designed to be welded into the main triangular truss to form an integral piece. The fabricated module are

presented in Fig. 1. The joints of two modules are created by male jugs and female jaws with the aid of the PTTC

technique [31]. As a new structure, it embodies characteristics of existing steel triangular trusses [34-37], T-type

beams [38,39] and plane trusses [25], but it is not equivalent to any of these conventional structural forms. That is,

the hybrid triangular deck-truss beam consists of a new structural form and advanced pultruded FRP profiles.

81 0.85-m depth. In the design, aluminum alloy extrusions with different cross-sections were used for the orthotropic

82 deck, connectors and verticals; additionally, pultruded hybrid fiber-reinforced polymer (HFRP) and glass

83 fiber-reinforced polymer (GFRP) tubes were selected for the lower chords and the web diagonals, respectively.

84 Here, the HFRP material is an admixture of E-glass fiber, carbon fiber and basalt fiber embedded in an isophthalic 
86 detailed connectors, geometries and mechanical properties of the profiles used.

\section{3. Experimental program}

\subsection{Specimen and test configuration}

In the experiments, two pre-fabricated full-scale modules were mounted to a 6-m cantilever specimen and

90 subjected to pure torsion. The specimen and the associate test configuration are illustrated in Fig. 2. At the fixed

91 end, a custom-manufactured steel frame was selected to support the specimen. On the steel frame, four steel male

92 jugs were welded to well connect the female jaws of the specimen using pins. At the free end, two reverse

93 concentrated loads $F$ (one pointing down and the other pointing up) provided by bob-weights were applied on the

94 two side upper male jugs to obtain the external torsional moment. The bob-weight was composed of a hanging

95 basket and several same steel blocks. The bob-weights were synchronously lifted by hand chain blocks with the aid

96 of a counterforce frame constructed from a series of off-the-shelf Bailey trusses. The load arm of the external

97 torsional moment was set at $1.2 \mathrm{~m}$. Four load levels were applied $(F=2 \mathrm{kN}, 3 \mathrm{kN}, 4 \mathrm{kN}$ and $5 \mathrm{kN})$. A loading and

98 unloading process $(\mathrm{F}=2 \mathrm{kN})$ was first repeated three times to minimize possible initial mounting inaccuracies and

99 to ensure that all loading setup and instruments worked properly.

\section{3.2. Measurement instrumentation}

In the test, the specimen was equipped with electric inclinometers and an Electric Total Station (ETS) to

measure the torsional angles and displacements, respectively. The corresponding instrumentation layout is shown in

103 Fig. 3(a). In the figure, four triangular cross-sections are shown as gauged and are referred to as A-1, A-2, A-3 and

104 A-4. The electric inclinometers were placed on the deck and along the middle main longitudinal beams.

105 Additionally, the specimen was equipped with calibrated unidirectional strain gauges to measure the longitudinal

106 strains. The instrumentation layout for the strain gages located on the tubular members and the orthotropic deck is 
107 shown in Figs. 4(b) and (c), respectively. Note that all of the tubular cross-sections of the lower chords and the web

108 diagonals are viewed from the free end to the fixed end along the specimen; the tubular cross-sections of the

109 verticals are viewed along the tubes from points "c" to "a" and then from "a" to "b". For all of the instrumented

110 tubular cross-sections, four strain gauges were laid equidistantly and counterclockwise. For the deck, three strain

111 gauges were located at the upper flange, lower flange and middle position at every instrumented I cross-section of

112 each main longitudinal beam (Z1, Z2 and Z3), and one strain gauge was mounted at the upper flange of each

113 secondary longitudinal beam (Z4 and Z5). The strain data were synchronously recorded by four static strain

114 indicator data acquisition systems connected to a computer. The weights of the bob-weights were recorded at each

115 load level, avoiding the need to measure the applied concentrated loads $F$ using a load cell or any other method.

\section{3.3. Experimental results}

\section{3.3.1. Deformation, displacement and torsion angle}

118 During the loading process, visual inspection revealed that the triangular deck-truss beam deformed torsionally,

119 as shown in Fig. 4. Similar to the main and secondary longitudinal I beams of the aluminum orthotropic deck, the

120 HFRP lower chords displayed an unambiguous torsionally deformed shape. Moreover, an apparent dislocation

121 appeared at the upper male jaw and female jug between two modules; i.e., the central line of the female jug was no

122 longer parallel to that of the male jaw. However, the analogous dislocation between the male jaw and female jug

123 connecting the lower chords of the two modules was minor and can be neglected. The dislocation is attributed

124 primarily to the interstice between the pin and pinhole combined with that between the upper male jaw and female

125 jug. The dislocation is a particular torsional behavior characteristic to this modular structure.

Figs. 5 and 6 show the variations of the displacements of the orthotropic deck and the lower chords, 
128 that the specimen deformed in the elastic region, as desired. Namely, the hybrid triangular deck-truss beam did not

129 distort under the applied torsional moment. In Fig. 5, the curve of point "b" is nearly symmetrical with that of point

130 "c" at every triangular cross-section for both the vertical and horizontal displacements; i.e., the two side

131 longitudinal beams deformed in a compatible manner. In addition, the displacements at point "o" are approximately

132 equal to zero (the corresponding curves are not shown). Thus, the orthotropic deck was almost rotated by the

133 middle main longitudinal I beam. It is concluded that the torsional center of the hybrid triangular deck-truss beam

134 without distortion was nearly collocated with that of the orthotropic deck. The aluminum orthotropic deck played a

135 critical role in the determination of the torsional center of the hybrid structure.

In Fig. 6, the displacements of point "a" at sections A-4 and A-3 are not shown because the sight-line from

137 ETS to notations was blocked in the test. The figure indicates that the HFRP lower chords deformed with a small

138 vertical upward displacement, and the maximum value at A-1 was only $8.9 \mathrm{~mm}$. However, the corresponding

139 horizontal displacement reached $124.6 \mathrm{~mm}$. These measurements indicate that in addition to the apparent torsional

140 behavior (as observed in Fig. 4), the HFRP lower chords underwent a large horizontal bending deformation. The

141 bending deformation of the HFRP lower chord was initiated by the rotation of the deck through the verticals and the

142 web diagonals. In other words, the verticals and the web diagonals played a key role in facilitating the rigid rotation

143 of the triangular cross-section and transferring the load from the deck to the lower chords.

144 Fig. 7 shows the measured relationship between the torsional moment and torsional rate (the slope is an

145 indication of torsional stiffness). In the figure, GJ-0, GJ-1+2, GJ-1 and GJ-2 represent the segment of the specimen

146 from section A-3 to A-2, from A-4 to A-1, from A-2 to A-1 and from A-4 to A-3, respectively; the torsional rate is

147 obtained by dividing the torsional angles (recorded by electric inclinometers) of every segment by the

148 corresponding segment length. It can be observed that except for the curve of GJ-0 below $3.6 \mathrm{kN} \cdot \mathrm{m}$, the four curves 
149 are essentially linear and parallel. The change of the slope of GJ-0 at $3.6 \mathrm{kN} \cdot \mathrm{m}$ is attributed primarily to the

150 aforementioned dislocation, as illustrated in Fig. 4. At torsional loads higher than $3.6 \mathrm{kN} \cdot \mathrm{m}$, the dislocation

151 disappeared and GJ-0 deformed in step with GJ-1 and GJ-2. By linear curve fitting, slopes with the following

152 values are obtained: $5.76,5.54,3.95$ and $4.51 \mathrm{kN} \cdot \mathrm{m}^{2} / \mathrm{deg}$ for GJ-0, GJ-1+2, GJ-1 and GJ-2, respectively. The

153 difference between GJ-1 and GJ-2 is caused primarily by the different restraining stiffness of the fixed end between

154 the two modules. The differences between GJ-1 and GJ-1+2 and between GJ-2 and GJ-1+2 arise primarily because

155 the torsional angle caused by the dislocation is included in the calculation of the torsional stiffness of GJ $-1+2$.

\section{$156 \quad$ 3.3.2. Stresses in the tubular members}

In the test, no cracking was audible during the loading process. Fig. 8 shows the measured load-stress curves

158 of three representative instrumented cross-sections (L1, L2 and L4) of the HFRP lower chords. The figure

159 demonstrates that the axial stresses on the lower chord were minor and can be neglected. However, certain bending

160 stresses existed in both the vertical plane (A-C plane) and the horizontal plane (B-D plane). The bending stresses at

161 points B and D were much larger than those at points A and C; i.e., the lower chords primarily bore out-of-plane

162 (horizontal-plane) bending moments rather than in-plane (vertical-plane) ones. This stress state correlates well with

163 the corresponding deformation of the lower chords, which underwent large horizontal deformation but small

164 vertical displacement (see Fig. 6). At the same tubular cross-section, the curves of points B and D are nearly

165 symmetrical, as are the curves of points A and C. This finding indicates that the tubular cross-sections of the lower

166 chords were in an almost pure bending state in both the vertical and horizontal planes. In addition, the horizontal

167 bending stress does not gradually increase from the free end to the fixed end, indicating that the lower chord cannot

168 be simply classified as a cantilever beam subjected to a concentrated load.

169 Fig. 9 shows the measured load-stress curves of the instrumented cross-sections D4 and D2 of the GFRP web 
170 diagonals. The curves of D1 and D3/D5 are not shown because their behavior was similar to those of D2 and D4,

171 respectively. This figure demonstrates that at the same tubular cross-section, the bending stress in the A-C plane

172 was much smaller than that in the B-D plane; the axial stress was also much smaller and can be neglected. Similar

173 to the lower chords, the web diagonals primarily bore an out-of-plane bending moment rather than an in-plane ones

174 and an axial force. Moreover, the bending stress at points D and B of D4 indicates in a compression and tension

175 state, respectively. These stress states are opposite those of D2 and D1, in which the bending stress at point D was

176 under tension whereas point B was under compression. That is, the web diagonals with different inclination display

177 an opposite out-of-plane bending direction. This contrast occurs primarily because the torsional angles of the

178 triangular cross-sections increased from the fixed end to the free end along the bridge axis; under this condition, the

179 deformation at the lower end of D4 occurred relative to that at its upper end, whereas the deformation at the lower

180 end of D2 was relative to that at its upper end. Thus, the opposite horizontal bending moments were generated in

181 D4 and D2 with an opposite inclination. From another point of view, if all of the triangular cross-sections were to

182 rotate around the middle longitudinal beam with same torsional angle, all of the web diagonals would deform

183 in-step with the same angles and the above horizontal bending moment would be equal to zero.

Fig. 10 shows the measured load-stress curves of the tubular cross-sections V1, V2 and V3 of the vertical.

185 Because of space confinements, the curves of other tubular cross-section are not shown because they exhibited

186 similar stress states. The figure shows that at the two end cross-sections (V1 \& V3), the bending stresses at points B

187 \& D were much larger than those at points A \& C, and the axial stress approached zero. However, at the middle

188 cross-section (V2), the bending stresses at points B \& D and A \& C and the axial stress were nearly equal to zero.

189 These measurements indicate that the verticals bore a regular in-plane bending state (in the diagonal plane parallel

190 to the bridge axis). The in-plane bending stresses were caused primarily by the frame effect of the Vierendeel truss 
191 composed of the side longitudinal I beams, the verticals and the lower chords. When the cantilever Vierendeel truss

192 was subjected to a concentrated load (caused by the applied torsional moment) at the free end, a large bending

193 moment distributed as a frame effect was generated.

\section{3.3.3. Stresses in the longitudinal I beams}

Fig. 11(a) presents the measured stresses in the longitudinal I beams of the orthotropic deck at $6.0 \mathrm{kN} \cdot \mathrm{m}$. It can

196 be observed that the longitudinal I beams exhibited a complicated stress distribution, which was caused primarily

197 by the spatial effect of the structure under torsion. In the two side I beams (Z1 and Z3), especially at their lower

198 flange (shown in blue), the stresses were of a similar order of magnitude to those in the tubular members. The

199 stresses in Z1 and Z3 were much larger than those in the middle beam Z2, which correlates well with the

200 corresponding deformation (i.e., the vertical displacements of Z1 and Z3 were much larger than those of Z2). This

201 difference arises primarily because the orthotropic deck rotated around the beam Z2. The results indicate that the

202 two side main longitudinal I beams carried much more of the applied torsion moment than the middle one.

203 In addition, the stresses in Z1 and Z3 were much larger than those in Z4 and Z5, mainly because the secondary

204 longitudinal I beams Z4 and Z5 were broken at the jointing segments and the fixed end, which is much different

205 from the case of the continuous main ones Z1 and Z3. When the triangular deck-truss structure was subjected to a

206 torsional moment, the non-restrained secondary longitudinal I beams exhibited no deformation and minimal stress

207 was induced. Thus, compared to the secondary longitudinal I beams, the two side main longitudinal I beams played

208 a much more critical role (in terms of vertical bending acting as a frame effect) in carrying the applied torsional

209 moment for the spatial structure. The contribution of the secondary longitudinal I beams can be neglected.

210 Furthermore, at every measured I cross-section of Z1 and Z3, the stresses at the upper flange (black font),

211 lower flange (blue font) and middle position (red font) were not equal. That is, stress arose not only from the pure 
212 bending but also from axial forces. However, compared to the bending stresses, the axial stresses were much

213 smaller and can be neglected. Moreover, the two beams bore a symmetrical stress state, which correlates well with

214 the measured symmetrical vertical deformation (see Fig. 5). As illustrated in Fig. 11(b), both Z1 and Z3 bore a

215 segmental bending stress state, which matches well with that of the verticals. This finding is attributed primarily to

216 the aforementioned frame effect of the Vierendeel truss. For the bilateral Vierendeel trusses, the verticals can be

217 considered to be elastic supports of the two side beams. From another point of view, if the verticals were removed

218 from the Vierendeel trusses, the two side beams would be in a cantilever condition. However, with the verticals

219 present, the two side beams are segmentally restrained and the stresses are redistributed.

\section{4. Finite element analysis}

\section{$221 \quad$ 4.1. Finite element modeling}

From the experiments, it is concluded that the deformation of the lower chords primarily originates from the

223 rotation of the deck through the verticals and the web diagonals; the applied torsional moment is resisted mainly by

224 the vertical bending of the Vierendeel trusses, the out-of-plane bending of the web diagonals, the torsion of the

225 main longitudinal I beams and the lower chords. To further understand the roles of the verticals and the web

226 diagonals in the torsional mechanism, the structural responses were numerically investigated by removing the

227 individual primary truss members with same type from the original structure prior to any load application. The

228 numerical analysis was conducted using ANSYS 13.0. The finite element (FE) model of the specimen was first

229 built and is referred to as M-1, as illustrated in Table 1. In addition, four other unique conditions were established

230 for comparison. M-2 corresponds to the removal of all of the verticals from M-1; M-3 corresponds to the removal

231 of all of the web diagonals from M-1; M-4 corresponds to the removal of all of the web diagonals and the four

232 verticals (two verticals in the mid-span of every module) from M-1; and M-5 corresponds to the removal of all of 
the tubular members (only deck with hinge joints) from M-1.

In the FE models, the Shell-63 element was employed to model the thin slab of the deck; the Beam-188

235 element was used to model the crisscrossing I beams, tubular members and connectors. The connectors were

236 simplified as segments of the corresponding truss members. Material and geometrical non-linear effects were not

237 considered. The generalized Hook's laws of linear elastic anisotropic and isotropic materials [40] are used as the

238 constitutive material laws of the pultruded FRP profiles and the aluminum alloy extrusions, respectively. The

239 engineering constants used for the generalized Hook's laws are summarized in [31]. In M-1 M-4, the appropriate

240 displacement boundary constraint for the hinge joints was achieved by releasing a rotational DOF; in M-5, the

241 corresponding nodes of the connectors were set as rigid to ensure convergence. In accordance with the test, four

242 load levels were evaluated. The dead weight was not considered.

\section{4.2. Validation of the original FE model}

Fig. 12 compares the numerical torsional stiffness with experimental results for two modules of the original

structure. The numerical torsional stiffness was obtained by linear fitting of the torsional moment as a function of

246 torsional rate of M-1. It is found that the numerical linear curves lie close to the measured ones, especially for GJ-1.

247 The torsional stiffness of GJ-1 and GJ-2 is numerically calculated to be 4.17 and $3.57 \mathrm{kN} \cdot \mathrm{m}^{2} / \mathrm{deg}$, respectively. For

248 GJ-1 and GJ-2, the discrepancy of the torsional stiffness between numerical and experimental results is

249 approximately $7.5 \%$ and $11.6 \%$, respectively. It appears that, besides experimental errors, the discrepancy is caused

250 primarily by different boundary constrains, spatial effects, and local configurations in the FE model compared to

251 the actual specimen. Additionally, it is likely that the large numerical value of GJ-1 compared to GJ-2 arises

252 because the restraint stiffness of GJ-1 in M-1 is larger than that of GJ-2; the aforementioned dislocation between

253 the male jaw and female jug cannot be modeled in sufficient detail for M-1 to replace the actual condition. 
Fig. 13 compares the numerical stress with experimental results for several representative tubular

255 cross-sections. Because of the similar analysis results, as described herein, the comparisons for other tubular

256 cross-sections are not shown. The figure demonstrates that the numerical values correlate well with the measured

257 results; the maximum discrepancy is approximately $15.6 \%$. In addition, the numerical results show that the lower

258 chords and the web diagonals bear primarily out-of-plane bending stress, rather than the axial stress and in-plane

259 bending stress; the verticals bear primarily in-plane bending stress, rather than the axial stress and out-of-plane

260 bending stress; and the web diagonals with opposite inclination bend in an opposite directions, which holds true for

261 the two ends of the verticals. These numerical stress distributions correlate well with the measured results.

262 Furthermore, it is confirmed from the numerical contours that the bending moment in the Vierendeel trusses exhibit

263 a bending state with a type of frame effect (see Fig. 14a); the lower chord bears a large torsional moment (see Fig.

264 14b), in good agreement with the experimental deformation (see Fig. 4). Thus, it is concluded from the above

265 comparisons that the torsional responses of the structure can be well simulated by the established FE model.

\section{4.3. Comparison of the different FE models}

For the five FE models, representative deformations were first compared, including the displacements and the

268 torsional angles at the cantilever triangular cross-section, as summarized in Table 1. The results indicate that when

269 all of the verticals are removed, the vertical displacements $z(a), z(b)$ and $z(c)$ of $M-2$ are approximately 2.4 times

270 those of M-1. The two side longitudinal I beams exhibit large horizontal displacements $y(b)$ and $y(c)$, which are

271 approximately 5.4 and 6.1 times those of M-1, respectively. Furthermore, the orthotropic deck and the lower chords

272 rotate with a much larger angle of $22.1^{\circ}$ and $13.9^{\circ}$, respectively. The angle $\theta_{1}$ is as much as $59.5 \%$ larger than $\theta_{2}$.

273 Namely, the line a'-o' is no longer perpendicular to line b'-c', indicating that the triangular cross-section displays an

274 apparent distortion. The large deformation discrepancy between M-2 and M-1 arises primarily because the two side 
275 longitudinal I beams and the lower chords are no longer restrained by the verticals in M-2.

276 However, when all of the web diagonals are removed, the values $y(a), z(b)$ and $z(c)$ of $M-3$ are only

277 approximately 1.1 times those of $\mathrm{M}-1$, and the values $\mathrm{y}(\mathrm{b})$ and $\mathrm{y}(\mathrm{c})$ are still minimal. In addition, the values $\theta_{1}$ and

$278 \theta_{2}$ are similar, indicating that the deformed triangular cross-section is not distorted. The above comparison indicates

279 that in the original structure, compared to the GFRP web diagonals, the aluminum verticals play a much more

280 critical role in facilitating the rigid rotation of the entire triangular cross-section along with the coordinated

281 deformation of the orthotropic deck and the lower chords.

282 When the two middle verticals of every module are removed from M-3, the values $\theta_{1}$ and $\theta_{2}$ in M-4 are still

283 close to each other, indicating that the deformed triangular cross-section is still not distorted. However, in

284 comparison with $\mathrm{M}-3$, the values $\mathrm{z}(\mathrm{b}), \mathrm{z}(\mathrm{c}), \mathrm{y}(\mathrm{a}), \theta_{1}$ and $\theta_{2}$ in M-4 are increased by approximately $25.7 \%, 29.0 \%$,

$28527.7 \%, 28.2 \%$ and $27.9 \%$, respectively. This change occurs primarily because when the two middle verticals are

286 removed, the aforementioned frame effect of the bilateral Vierendeel truss is weakened. Furthermore, when all of

287 the other verticals are removed from M-4, the deformation of the orthotropic deck in M-5 increases by a large

288 extent with an angle $\left(\theta_{1}\right)$ of $29.20^{\circ}$. This increase is attributed to the frame effect completely disappearing under

289 this unique condition. These results indicate that the frame effect of the bilateral Vierendeel truss has a large

290 influence on the overall torsional deformation of the original structure.

In addition to the deformations, the consequences of removing the primary truss members on the stress state of

292 the main longitudinal beams and the lower chords were studied. Fig. 15 shows the in-plane (vertical plane) bending

293 stress contours in Z1 Z3 of M-2 M-4 at $6.0 \mathrm{kN} \cdot \mathrm{m}$; the stress contour of M-1 was presented in Fig. 11(b). Because

294 of space confinements and the similar analysis results, the stress state in the lower chords is no shown. The figure

295 indicates that the stress of M-3 exhibits a segmental bending state similar to that of M-1. The stress at the crossover 
296 points of Z1\&Z3 and the verticals exhibits several sudden changes caused primarily by the frame effect. The

297 distributions of the two contours approach each other, and the maximum discrepancy of the values is approximately

298 10.4\%. In fact, Z1 Z3 can be considered a cantilever beam restrained segmentally by the verticals in M-1 and M-3.

299 However, the stress contour in M-2 indicates a two-region bending state and the stress at the connectors is equal to

300 zero, which constitutes apparent difference with the behavior of M-1 and M-3. The difference occurs because in

$301 \mathrm{M}-2$, the frame effect disappears and Z1\&Z3 are restrained only by the web diagonals through the main cross I

302 beams. The values at most segments of Z1 Z3 in M-2 are larger than those of the corresponding segments in M-1

303 and M-3. Thus, the load transfer contributed by the web diagonals is much weaker than that of the verticals.

304 In M-4, the stress contour indicates a segmental bending state with fewer sudden changes than that of M-3.

305 Because of the removal of the two middle verticals, the sudden changes at the corresponding crossover points

306 disappear. The maximum discrepancy between M-3 and M-4 is approximately $38.9 \%$. In M-5, because the

307 longitudinal I beams are no longer restrained by the verticals, the stress distribution greatly approaches that of a

308 cantilever beam. Under this condition, the load subjected to the deck is no longer transferred to the lower chords.

309 These numerical results confirm further that compared to the web diagonals, the verticals play a much more critical

310 role (in terms of the frame effect) in transferring the load from the orthotropic deck to the lower chords.

Altogether, the torsional mechanism can be further understood as follows. When subjected to pure torsion, the

312 deformation of the lower chords primarily originates from the rotation of the orthotropic deck through the verticals

313 and the web diagonals. The distribution of the torsional load on the longitudinal members, the in-plane bending of

314 the bilateral Vierendeel trusses and the out-of-plane bending of the web diagonals contributes considerably to the

315 maintenance of the external torsional moment. Compared to the web diagonals, the verticals play a much more

316 critical role in transferring the load from the deck to the lower chords, as well as facilitating the rigid rotation of the 
317 entire triangular cross-section of the hybrid structure.

\section{5. Discussion}

319 It can be concluded from the experimental and numerical results that the hybrid triangular deck-truss beam

320 exhibits specific structural responses under the pure torsion condition. Reflecting the overall torsional behavior of

321 the rigid triangular cross-section, the HFRP lower chords and the corresponding pre-tightened teeth connectors

322 themselves display large torsional and bending deformations. Compared to conventional planar trusses $[14,15,25]$

323 and steel triangular trusses [34-37], the bilateral Vierendeel trusses of this hybrid triangular deck-truss beam have a

324 smaller flexibility factor, leading to a poorer overall torsional stiffness.

325 In addition, the hybrid structure exhibits a complicated stress state, especially in the FRP tubular profiles.

326 Large bending and shear stresses are induced in the FRP members, which hinders application of the advantages of

327 the unidirectional pultruded FRP materials. The HFRP lower chords primarily bear an out-of-plane bending

328 moment and torque; the GFRP web diagonals primarily bear an out-of-plane bending moment; and the verticals

329 primarily bear an in-plane bending moment. This stress state does not match that of the initial design, in which

330 these member profiles are only subjected to axial forces; i.e., they are designed for a pure tension-compression state.

331 In fact, if isotropic aluminum is used for the lower chords, the bending and torsional problem does not need to be

332 highlighted. However, it should be given significant consideration in the case of anisotropic composite materials

333 because the interlaminar shear stress of the extrusion-type FRP profiles is low. When subjected to certain bending

334 and shear stresses, these FRP profiles will bear a complicated and deleterious stress state, which may cause damage

335 to the composites. The same analysis results can be applied to the pre-tightened teeth connectors for FRP tubes.

336 Thus, the triangular deck-truss beam cannot be solely used as a structure subjected to off-axis load and torsion.

337 If it is used alone in further engineering applications, certain necessary structural improvements are needed. For 
338 example, the local structures at the two ends of the verticals and the web diagonals (which bear large bending

339 moment) need to be strengthened to obtain a reliable connection, e.g., by adding triangular plates (similar to that of

340 the vertical plane, see Fig. 1) with reliable welding. Moreover, these FRP tubes cannot be simply designed as pure

341 tension-compression members, and the axial force, bending moment, shear force and torque should be included in

342 the initial design to enable a larger bearing capacity and enable better structural properties.

343 Furthermore, to obtain a larger torsional stiffness of the entire structure and to improve the stress states of the

344 FRP members, the original structure in question should be re-designed. First, the secondary longitudinal I beams

345 of the orthotropic deck between two adjacent modules should be connected by male jugs and female jaws. This

346 change is recommended because when the secondary longitudinal beams between two adjacent modules are

347 connected, their bending and torsion participate in carrying the external torsional moment. Second, the bilateral

348 Vierendeel trusses of the original structure should be changed to a conventional planar truss (e.g., a Warren truss,

349 Pratt truss or Howe truss [15]). In this way, the flexibility factor of the two side trusses is enlarged and their

350 in-plane vertical bending carries much more of the external torsional moment. Third, the structural form of the

351 original lower chord with a single FRP tube can be replaced by a form of planar truss [15]. This modification will

352 increase the horizontal bending stiffness and torsional stiffness of the lower chords and thus increase the overall

353 torsional stiffness of the structure; furthermore, the bending moment of the original lower chord with its single tube

354 will be converted into axial forces in the trussed members of the replaced planar truss. These improvements are

355 significant to this type of hybrid structure, especially for those with large spans. The detailed structural

356 improvement and optimization procedures will be implemented in further studies, in which the hybrid triangular

357 deck-truss beam will be used solely as a structure subjected to off-axis load and torsion.

\section{6. Conclusions}


In this paper, both experimental and numerical research studies were conducted to investigate the torsional

response of the modular FRP-aluminum triangular deck-truss beam. The following conclusions pertain specifically

to this new hybrid structure:

(1) Under the elastic pure-torsion condition, the hybrid structure exhibited specific structural responses.

363 Reflecting the overall torsional behavior of the rigid triangular cross-section, the tubular lower chords and the main

364 longitudinal I beams themselves displayed large torsional and bending deformations. The torsional center of the

365 hybrid triangular deck-truss beam was essentially collocated with the center of the aluminum orthotropic deck. The

366 deformation of the lower chords was initiated by the rotation of the orthotropic deck through the verticals and the

367 web diagonals. Compared to the web diagonals, the verticals played a much more critical role in facilitating the 368 rigid rotation of the triangular cross-section. The torsional stiffness of the fixed and free modules was 369 experimentally found to be approximately 4.51 and $3.95 \mathrm{kN} \cdot \mathrm{m}^{2} / \mathrm{deg}$, respectively.

(2) The hybrid structure exhibited a complicated stress state in the trussed members, especially the pultruded

371 FRP tubes. The HFRP lower chords themselves were subjected primarily to a large torque and out-of-plane bending

372 moment; the GFRP web diagonals bore primarily a large out-of-plane bending moment. Because of the frame effect

373 of the bilateral Vierendeel trusses subjected to an in-plane load, the two side main longitudinal I beams and the

374 tubular lower chords were exposed to segmental vertical and horizontal bending stress states along the bridge axis,

375 respectively; additionally, the verticals underwent regular bending from the large moment at their two ends. This

376 bending stress state of the bilateral Vierendeel trusses was similar to that of an identical Vierendeel truss subjected

377 solely to a cantilever concentrated force. The complicated stress state did not match that of the initial design, in 378 which the tubular profiles were designed as tension-compression members subjected to axial force only. 
380 in-plane vertical bending of the bilateral Vierendeel trusses, the out-of-plane horizontal bending of the GFRP web

381 diagonals, and the torsion of the HFRP lower chords and the aluminum main longitudinal I beams. Compared to the

382 GFRP web diagonals, the aluminum verticals played a much more critical role in transferring the load from the

383 orthotropic deck to the lower chords. The frame effects of the bilateral Vierendeel trusses and the torsion of the

384 lower chord should be given ample consideration in the load transfer mechanism for this spatial structure.

385 (4) The hybrid structure exhibited a poor torsional stiffness. Moreover, the pultruded FRP members and the

386 pre-tightened teeth connectors themselves displayed large torsional and bending deformations combined with a

387 complicated stress state, which limited the advantages of the unidirectional pultruded FRP materials. Thus, if this

388 new hybrid triangular deck-truss beam is further used alone as a structure subjected to an off-axis load with a large

389 torsional moment, the original structure in question should be strengthened or re-designed and structural

390 improvements are necessary. These detailed structural improvements and optimization procedures will be

391 implemented in future studies.

\section{Acknowledgments}

393 The research work reported in this paper is supported by the National Science Foundation of China under

394 Grant Nos. 51408606 and 11372355, the Major State Basic Research Development Program of China (973 Program)

395 under Grant No. 2012CB026202 and the National Science and Technology Support Program of China under Grant

396 No. 2014BAB15B.

397 References

[1] Awad ZK, Aravinthan T, Yan ZG, Gonzalez F. A review of optimization techniques used in the design of fibre composite structures for civil engineering applications. Mater Des 2012; 33:534-44.

[2] Hollaway LC. A review of the present and future utilization of FRP composites in the civil infrastructure with reference to their important in-service properties. Constr Build Mater 2010; 24:2419-45.

[3] Zhao XL, Zhang L. State-of-the-art review on FRP strengthened steel structures. Eng Struct 2007; 29:1808-23. 
[4] Feng P, Ye LP, Teng JG. Large-span woven web structure made of fiber-reinforced polymer. J Compos Constr 2007; 11(2): 110-19.

[5] Wang X, Shi JZ, Wu G, Yang L, Wu ZS. Effectiveness of basalt FRP tendons for strengthening of RC beams through the external prestressing technique. Eng Struct 2015; 101:34-44.

[6] Sonia YA, Julia DC, Thomas K. System transverse in-plane shear stiffness of pultruded GFRP bridge decks. Eng Struct 2016; 107:34-46.

[7] Zhang Y, Cai CS. Load distribution and dynamic response of multi-girder bridges with FRP decks. Eng Struct 2007; 29(8):1676-89.

[8] Gonilha JA, Correia JR, Branco FA. Structural behaviour of a GFRP-concrete hybrid footbridge prototype: Experimental tests and numerical and analytical simulations. Eng Struct 2014; 60:11-22.

[9] Yang X, Bai Y, Ding FX. Structural performance of a large-scale space frame assembled using pultruded GFRP composites. Compos Struct 2015; 133:986-96.

[10] Ji HS, Song WC, Ma JZ. Design, test and field application of a GFRP corrugated-core sandwich bridge. Eng Struct 2010; 32:2814-24.

[11] Farhey DN. Long-term performance monitoring of the Tech 21 all-composite bridge. J Compos Constr 2005; 9(3):252-62.

[12] Wight RG, Erki MA, Shyu CT. Development of FRP short-span deployable bridge - Experimental results. J Bridge Eng 2006; 11:489-98.

[13] Robinson MJ, Kosmatka JB. Development of a short span fiber reinforced composite bridge for emergency response and military applications. J Bridge Eng 2008; 13:388-97.

[14] Machacek J, Cudejko M. Longitudinal shear in composite steel and concrete trusses. Eng Struct 2009; 31:1313-20.

[15] Ozyurt E, Wang YC. Effects of non-uniform temperature distribution on critical member temperature of steel tubular truss. Eng Struct 2016; 116:95-106.

[16] Dou C, Guo YL, Zhao SY, Pi YL, Bradford MA. Elastic out-of-plane buckling load of circular steel tubular truss arches incorporating shearing effects. Eng Struct 2013; 52:697-706.

[17] Han QH, Xu Y, Lu Y, Jie Xu, Zhao QH. Failure mechanism of steel arch trusses: Shaking table testing and FEM analysis. Eng Struct 2015; 82:186-98.

[18] Rice JA, Foutch DA, Lafave JM, Valdovinos S. Field testing and analysis of aluminum highway sign trusses. Eng Struct 2012; 34:173-86.

[19] Hu N, Dai GL, Yan B, Liu K. Recent development of design and construction of medium and long span high-speed railway bridges in China. Eng Struct 2014; 74:233-41.

[20] Fan HL, Jin FN, Fang DN. Characterization of edge effects of composite lattice structures. Compos Sci Tech 2009; 69(11-12): 1896-903.

[21] Fan HL, Yang L, Sun FF, Fang DN. Compression and bending performances of carbon fiber reinforced lattice-core sandwich composites. Compos Part A 2013; 52:118-25. 
[22] Teixeira AMAJ, Pfeil MS, Battista RC. Structural evaluation of a GFRP truss girder for a deployable bridge. Compos Struct 2014; 110:29-38.

[23] Kostopoulos V. Design and construction of a vehicular bridge made of glass/polyester pultruded box beams. Plastics, Rubbers and Compos 2005; 34(4):201-7.

[24] Sedlacek G, Trumpf H. Development of a lightweight emergency bridge. Struct Eng Int 2004; 14(4): 282-7.

[25] Huang YF, Briseghella B, Zordan T, Wu QX, Chen BC. Shaking table tests for the evaluation of the seismic performance of an innovative lightweight bridge with CFST composite truss girder and lattice pier. Eng Struct 2014; 75:73-86.

[26] Keller T, Bai Y, Vallée T. Long-term performance of a glass fiber-reinforced polymer truss bridge. J Compos Constr 2007; 11(1):99-108.

[27] Iwao S, Itaru NSZK. Load-bearing properties of an FRP bridge after nine years of exposure [C]//.CICE 2010-The 5th International Conference on FRP Composites in Civil Engineering, September 27-29, 2010, Beijing, China.

[28] Bai Y, Yang X. Novel joint for assembly of all-composite space truss structures: conceptual design and preliminary study. J Compos Constr 2013; 17:130-38.

[29] Zhou A, Keller T. Joining techniques for fiber reinforced polymer composite bridge deck systems. Compos Struct 2006; 69:336-45.

[30] Pfeil MS, Teixeira AMAJ, Battista RC. Experimental tests on GFRP truss modules for dismountable bridges. Compos Struct 2009; 89(1):70-76.

[31] Zhang DD, Zhao QL, Huang YX, Li F, Chen HS, Miao DS. Flexural properties of a lightweight hybrid FRP-aluminum modular space truss bridge system. Compos Struct 2014; 108:600-15.

[32] Liu XP, Yu TL, Wang L. Bridge engineering. Beijing: Science Press; 2011.

[33] Zhang DD, Li F, Zhao QL, Duan YC. Analytical solutions of the torsional mechanism for a new hybrid fiber-reinforced polymer - aluminum twin-trackway space truss bridge. Adv Struct Eng 2016; 19(12): $1832-40$.

[34] Durfee RH. Review of triangular cross section truss systems. J Struct Eng - ASCE 1986; 112(5):1088-96.

[35] Reis A, Pedro JJO. Composite truss bridges: new trends, design and research. Steel Constr 2011; (3):176-82.

[36] Foss CF, Gander TJ. Jane's Military Vehicles and Logistics, Jane's Information Group, Surrey, United Kingdom, 1991.

[37] Han LH, Xu W, He SH, Tao Z. Flexural behaviour of concrete filled steel tubular (SFST) chord to hollow tubular brace truss: experiments. J Constr Steel Res, 2015; 109: 137-51.

[38] Deng YH, Phares BM, Steffens OW. Experimental and numerical evaluation of a folded plate girder system for short-span bridges - A case study. Eng Struct 2016; 116:26-40.

[39] Pathirana SW, Uy B, Mirza O, Zhu XQ. Flexural behaviour of composite steel-concrete beams utilising blind bolt shear connectors. Eng Struct 2016; 114:181-94.

[40] Shen GL, Hu GK, Liu B. Mechanics of composite materials. Beijing: Peking University Press; 2013. 
Table list:

Table 1 Comparison of the displacements and torsional angles at the cantilever triangular cross-section among the five FE models.

Table 1 Comparison of the displacements and torsional angles at the cantilever triangular cross-section among the five FEMs.

\begin{tabular}{|c|c|c|c|c|c|c|c|c|c|c|c|}
\hline \multirow{2}{*}{$\begin{array}{l}\text { Numerical } \\
\text { results }\end{array}$} & \multicolumn{4}{|c|}{ Vertical displacements / mm } & \multicolumn{4}{|c|}{ Horizontal displacements / mm } & \multicolumn{2}{|c|}{ Torsional angles / Deg. } & \multirow{2}{*}{$\begin{array}{l}\text { Schematics of the deformed } \\
\text { triangular cross-section }\end{array}$} \\
\hline & $z(a)$ & $z(b)$ & $z(c)$ & $z(0)$ & $y(a)$ & $y(b)$ & $y(c)$ & $y(0)$ & $\theta_{1}$ & $\theta_{2}$ & \\
\hline M-1 & 7.2 & 92.2 & -99.6 & -3.7 & -135.3 & 8.1 & -7.3 & 0.4 & 9.20 & 9.19 & \multirow[t]{2}{*}{$z_{t}$} \\
\hline M-2 & 16.6 & 217.2 & -234.6 & -8.7 & -204.4 & 43.5 & -44.7 & -0.6 & 22.12 & 13.87 & \\
\hline M-3 & 9.0 & 102.8 & -112.3 & -4.7 & -151.8 & 10.1 & -9.3 & 0.4 & 10.33 & 10.31 & \\
\hline M-4 & 14.7 & 129.2 & -144.9 & -7.8 & -193.8 & 16.0 & -15.7 & 0.2 & 13.20 & 13.19 & \\
\hline M-5 & 0 & 282.6 & -302.8 & -10.1 & 0 & 74.5 & -77.7 & -1.6 & 29.20 & . & $\ldots y$ \\
\hline \multicolumn{12}{|l|}{ Schematics } \\
\hline different & \multicolumn{3}{|c|}{ M-1 } & \multicolumn{2}{|c|}{ M-2 } & \multicolumn{3}{|c|}{ M-3 } & \multicolumn{2}{|c|}{ M-4 } & M-5 \\
\hline FEMs & \multicolumn{3}{|c|}{$\begin{array}{l}\text { Original model of } \\
\text { specimen }\end{array}$} & \multicolumn{2}{|c|}{$\begin{array}{l}\text { Removal of all the } \\
\text { verticals from M-1 }\end{array}$} & \multicolumn{3}{|c|}{$\begin{array}{l}\text { Removal of all the web } \\
\text { diagonals from M-1 }\end{array}$} & \multicolumn{2}{|c|}{$\begin{array}{l}\text { Removal of middle verticals } \\
\text { of each unit from M-3 }\end{array}$} & $\begin{array}{l}\text { Removal of all the web diagonals } \\
\text { and verticals from M-1 }\end{array}$ \\
\hline
\end{tabular}




\section{Figure list:}

Fig. 1. Hybrid space truss structure and its triangular module.

Fig. 2. Pure torsion test for triangular deck-truss beam. (a) Test configuration; (b) specimen.

Fig. 3. Instrumentation layouts for: (a) torsional angle and displacements; (b) strains on tubular trussed members; (c) strains on the "I" beams of the orthotropic deck.

Fig. 4. Deformation of the triangular deck-truss beam, the HFRP lower chords and the upper connector.

Fig. 5. Measured load-displacement curve for the orthotropic deck. (a) Vertical; (b) horizontal.

Fig. 6. Measured load-displacement curve for the lower chord. (a) Vertical; (b) horizontal.

Fig. 7. Measured torsional moment - torsion rate curves for the triangular deck-truss beam.

Fig. 8. Measured load-stress curves for the HFRP lower chords. (a) L1; (b) L4; (c) L2.

Fig. 9. Measured load-stress curves for the GFRP web diagonals. (a) D4; (b) D2.

Fig. 10. Measured load-stress curves for the aluminum verticals. (a) V1; (b) V2; (c) V3.

Fig. 11. Stress distribution on the longitudinal I beams of the orthotropic deck (MPa). (a) Measured results; (b) schematic of the stress state.

Fig. 12. Comparison of measured and numerical torsional stiffness for the specimen.

Fig. 13. Comparison of measured and numerical stresses for tubular members (MPa). (a) Lower chord; (b) web diagonal; (c) vertical.

Fig. 14. Internal force contour in the trussed members of M-1 (N.mm). (a) Bending moment in the Vierendeel truss; (b) torsional moment in the lower chord..

Fig. 15. Bending stress contours in the vertical plane for the main longitudinal I beams (MPa). (a) M-2; (b) M-3; (c) M-4; (d) M-5. 


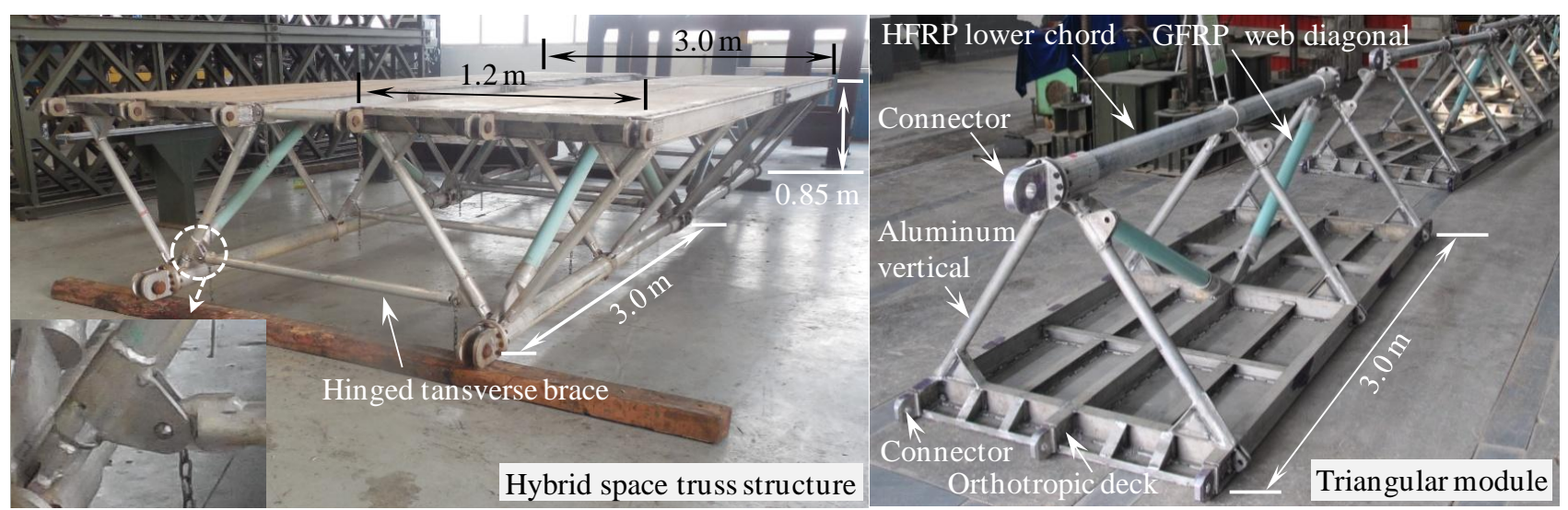

Fig. 1. Hybrid space truss structure and its triangular module. 
(a)

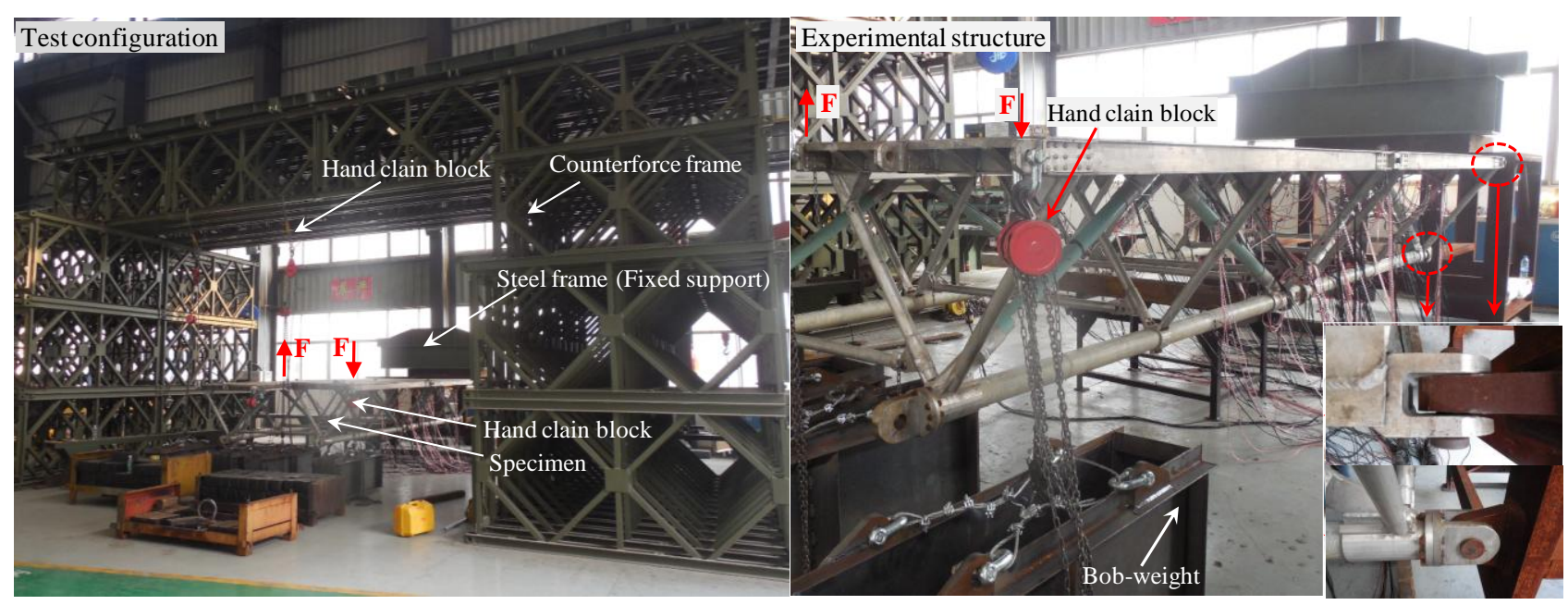

Fig. 2. Pure torsion test for triangular deck-truss beam. (a) Test configuration; (b) specimen. 
(a)

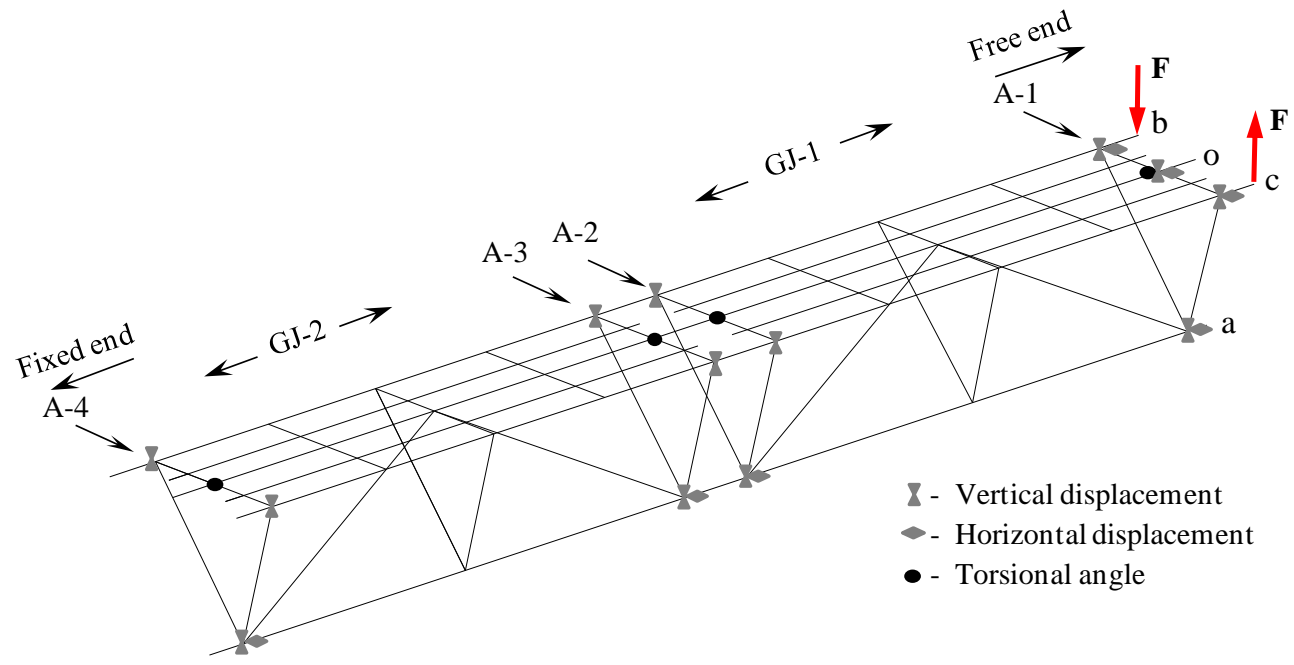

(b)

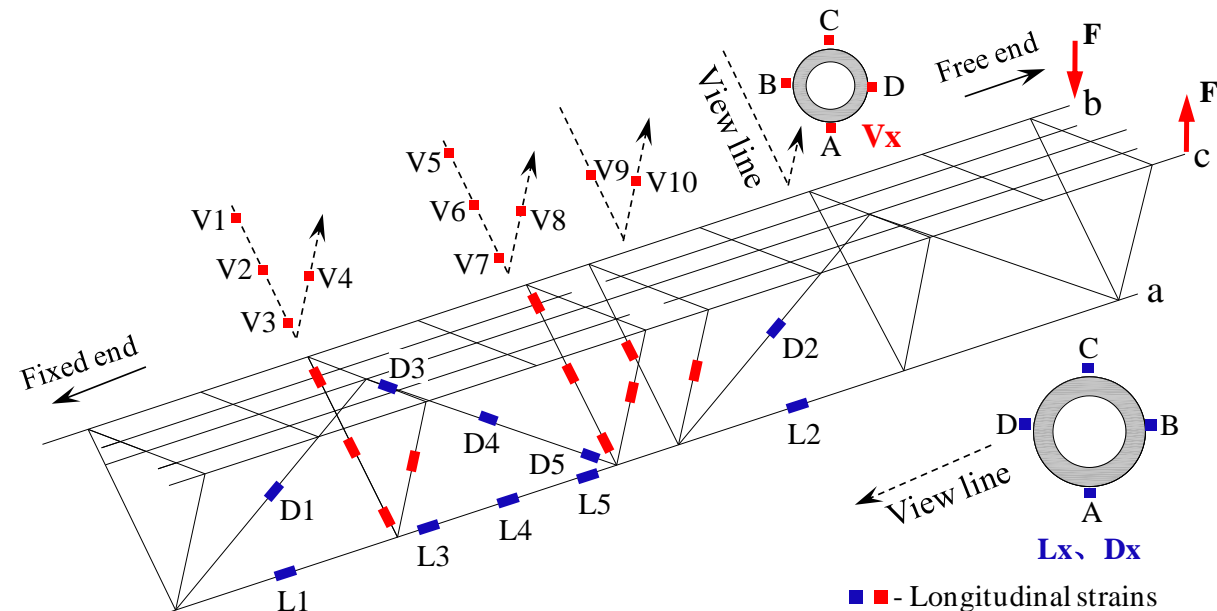

(c)

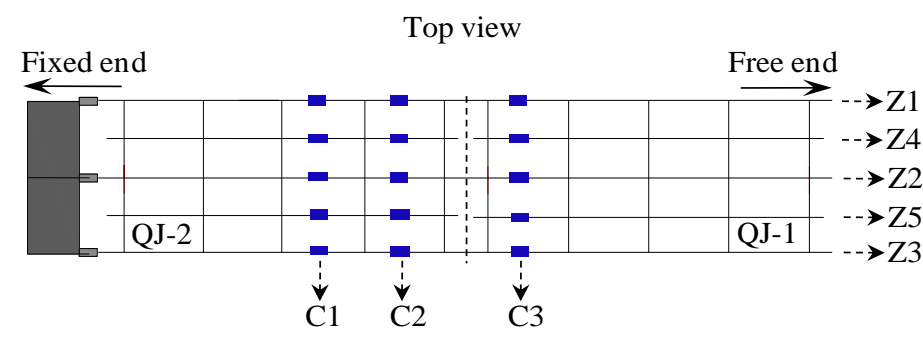

Front view

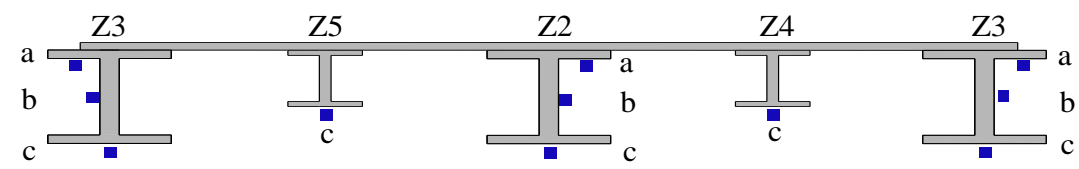

Detailed cross-section of the orthotropic deck

- - Longitudinal strains; Cx-Zy-z $\quad(x=1 \sim 3 ; \quad y=1 \sim 5 ; \quad z=a, b, c)$

Fig. 3. Instrumentation layouts for: (a) torsional angle and displacements; (b) strains on tubular trussed members; (c) strains on the "I" beams of the orthotropic deck. 


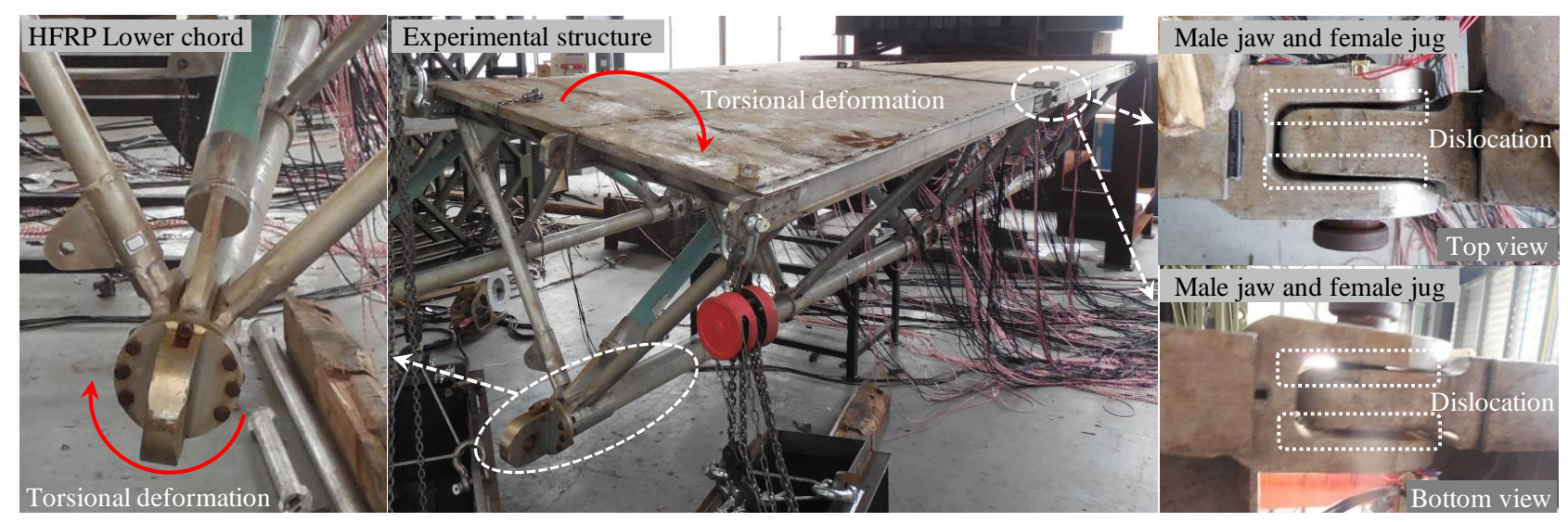

Fig. 4. Deformation of the triangular deck-truss beam, the HFRP lower chords and the upper connector. 
(a)

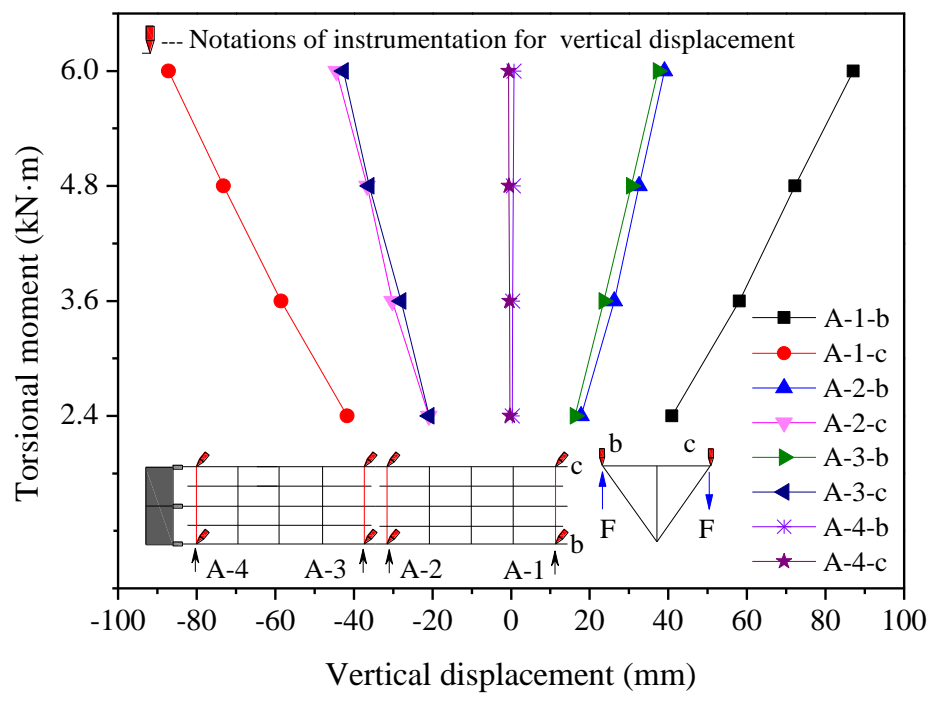

(b)

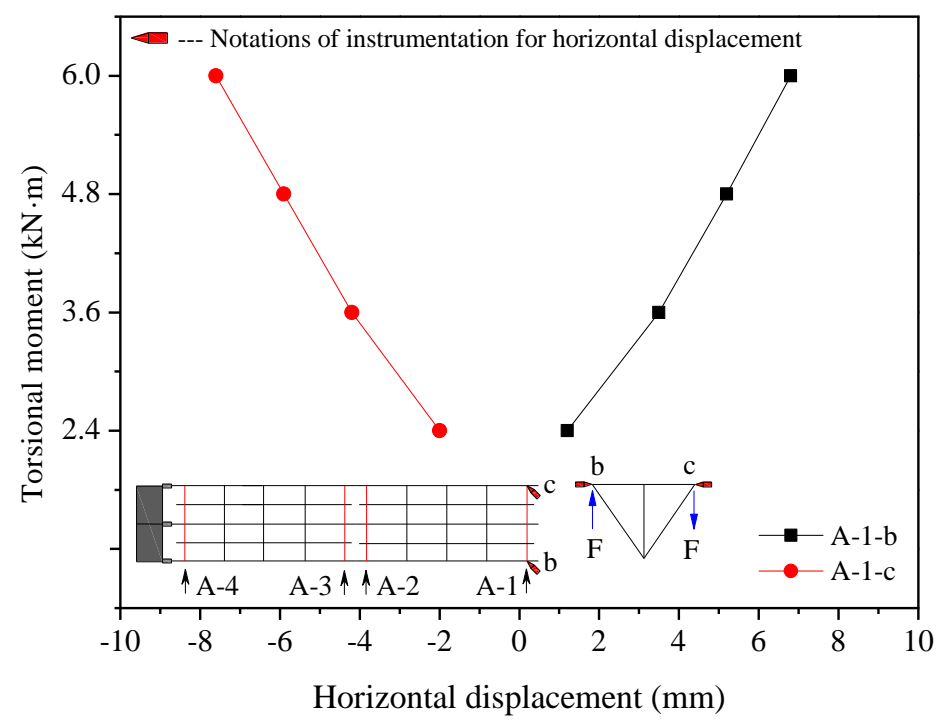

Fig. 5. Measured load-displacement curve for the orthotropic deck. (a) Vertical; (b) horizontal. 
(a)

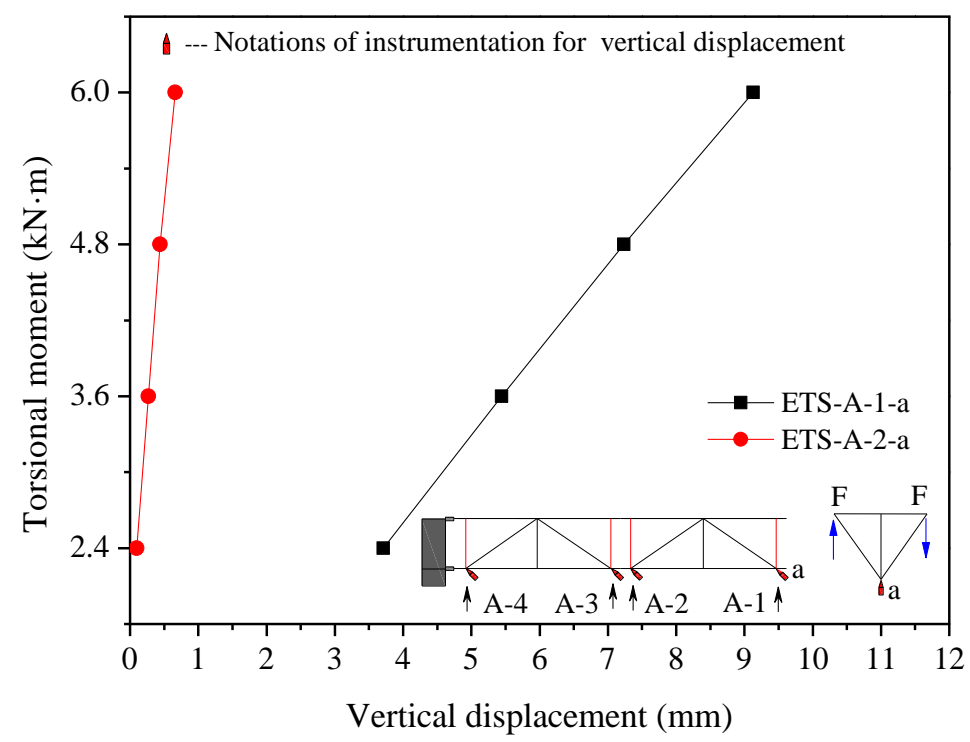

(b)

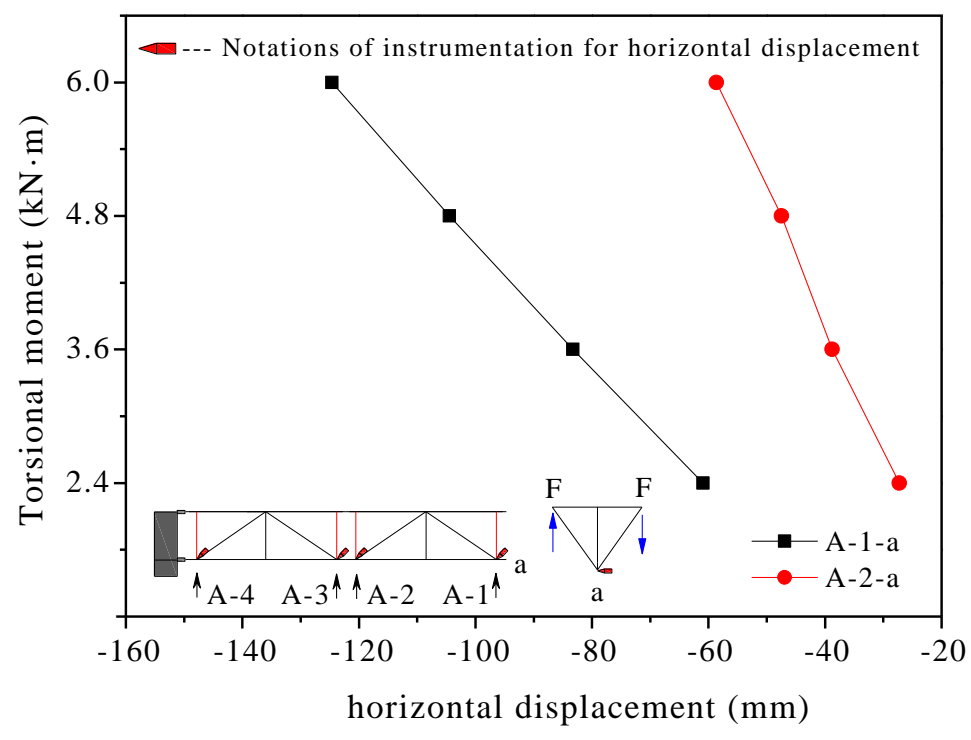

Fig. 6. Measured load-displacement curve for the lower chord. (a) Vertical; (b) horizontal. 


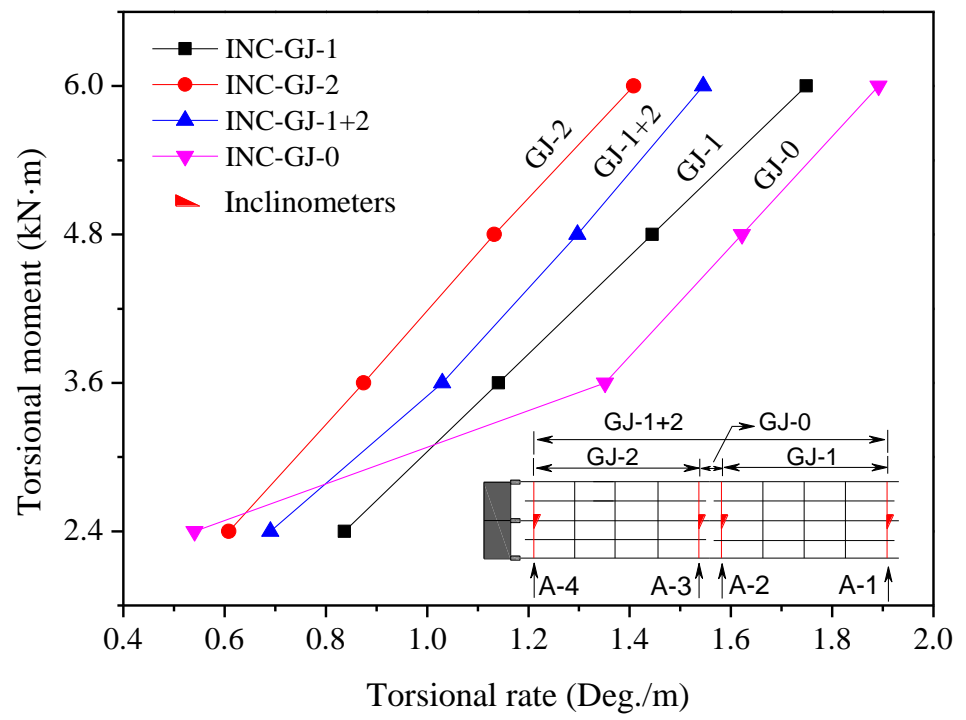

Fig. 7. Measured torsional moment - torsion rate curves for the triangular deck-truss beam. 
(a)

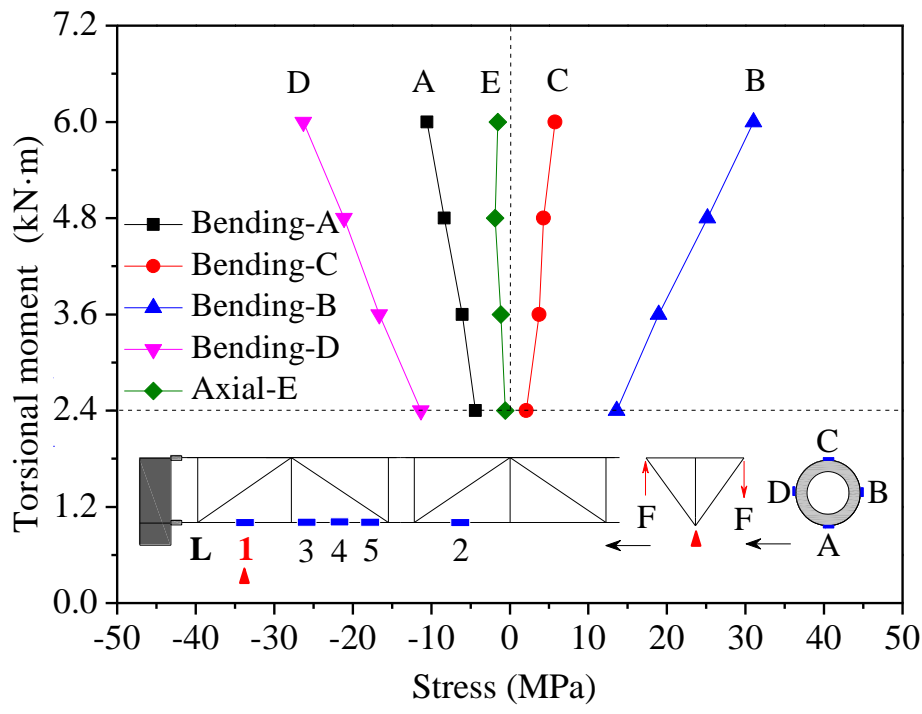

(b)

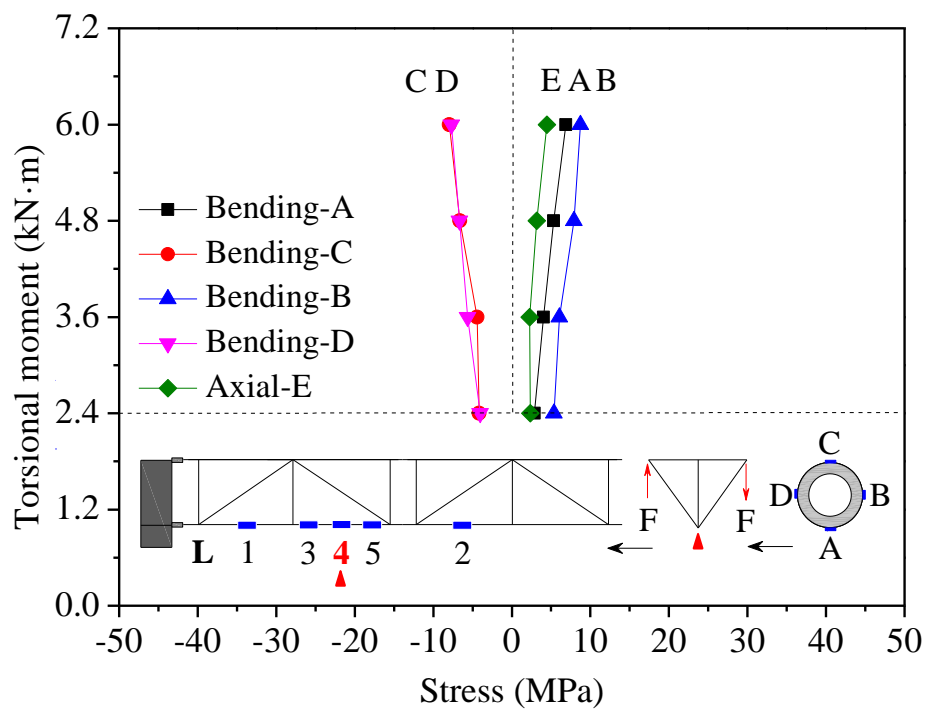

(c)

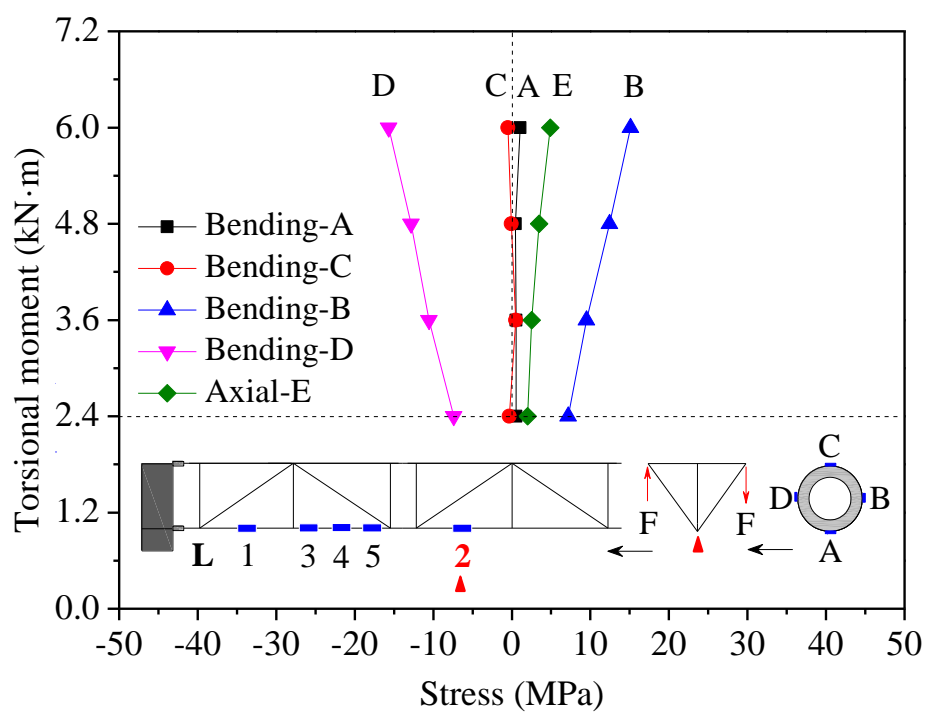

Fig. 8. Measured load-stress curves for the HFRP lower chords. (a) L1; (b) L4; (c) L2. 
(a)

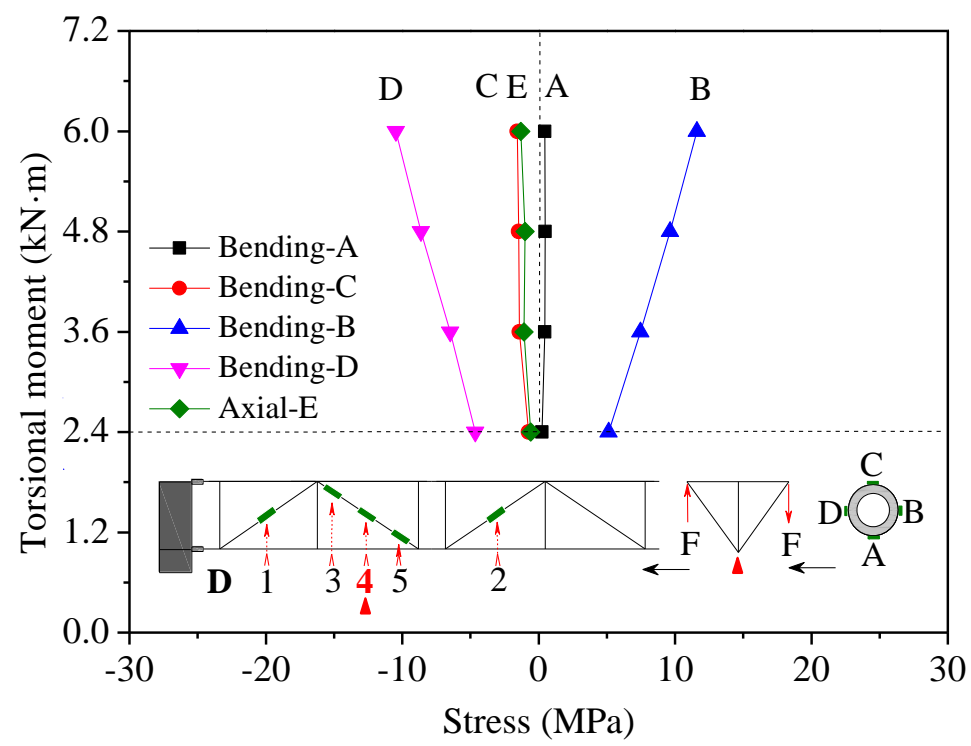

(b)

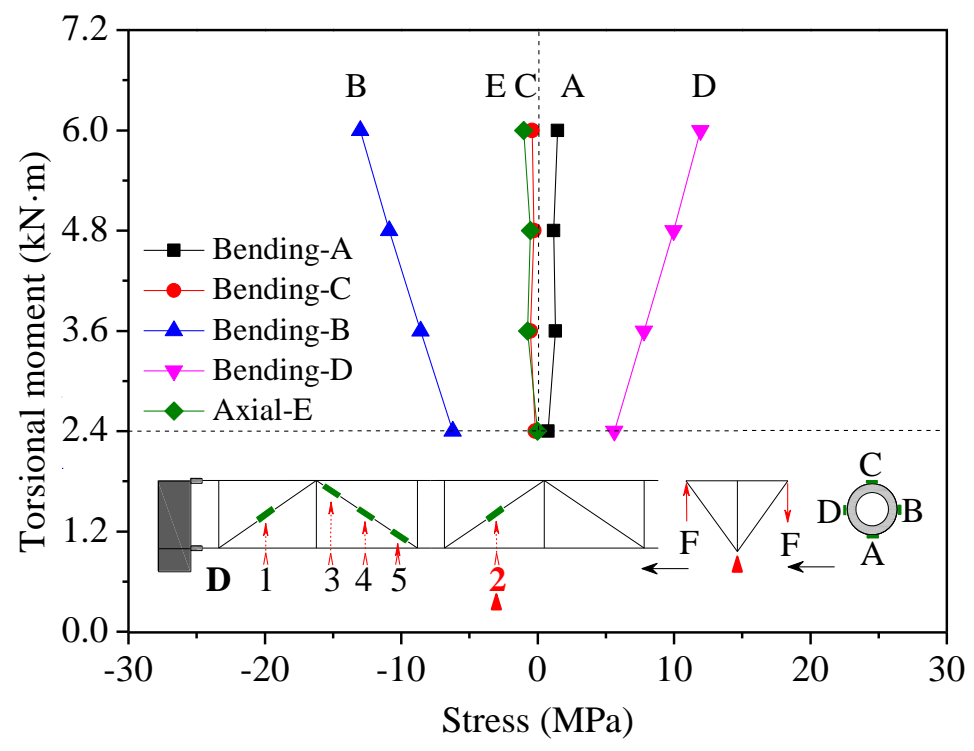

Fig. 9. Measured load-stress curves for the GFRP web diagonals. (a) D4; (b) D2. 
(a)

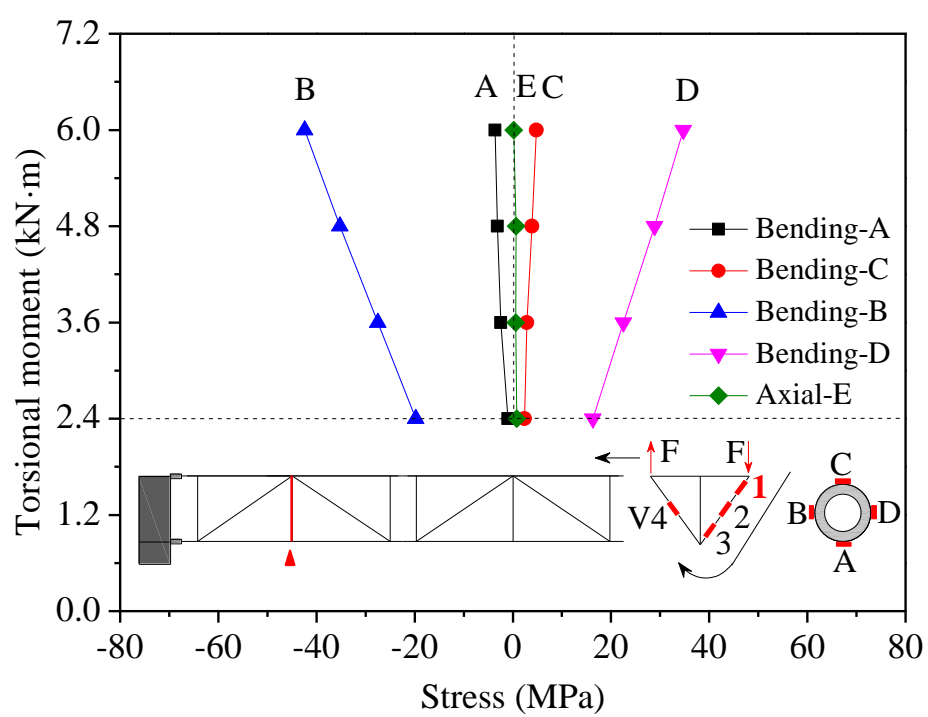

(b)

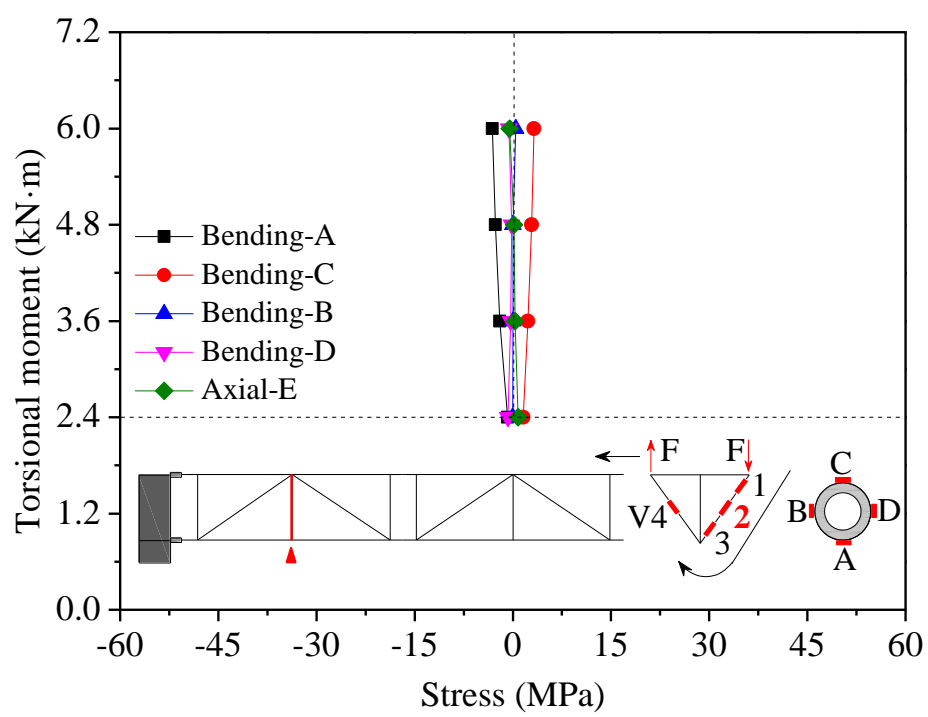

(c)

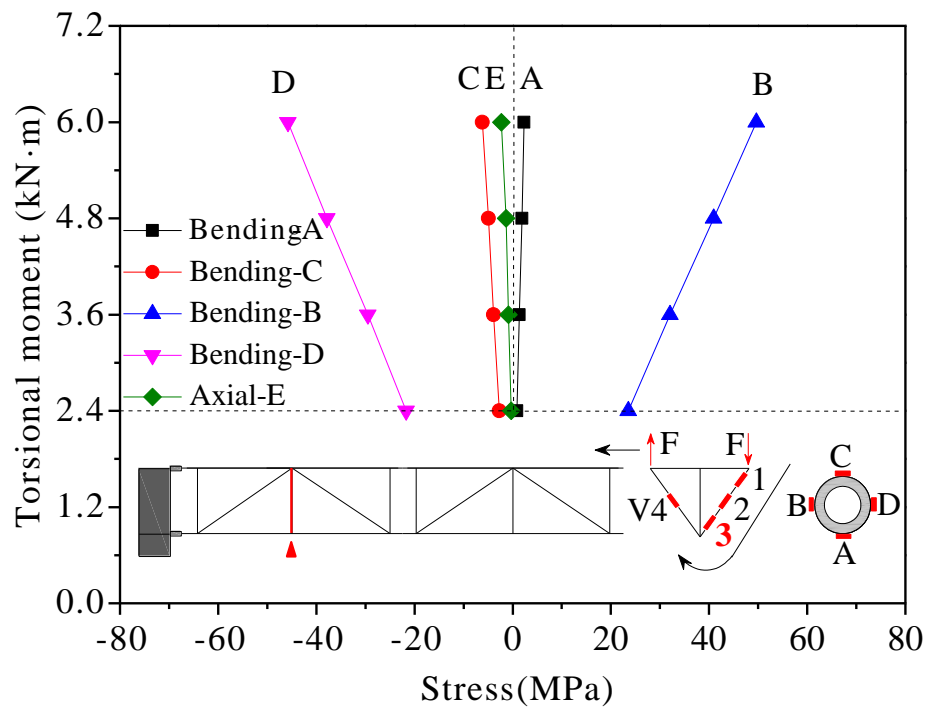

Fig. 10. Measured load-stress curves for the aluminum verticals. (a) V1; (b) V2; (c) V3. 
(a)

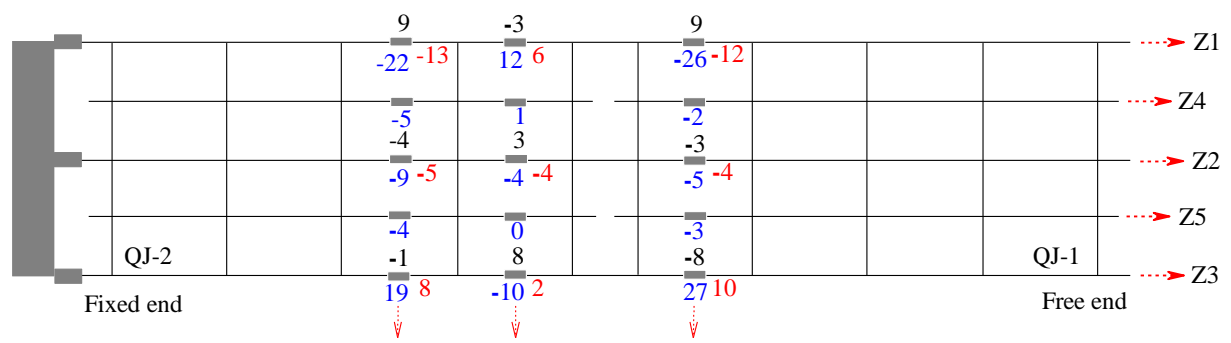

(b)

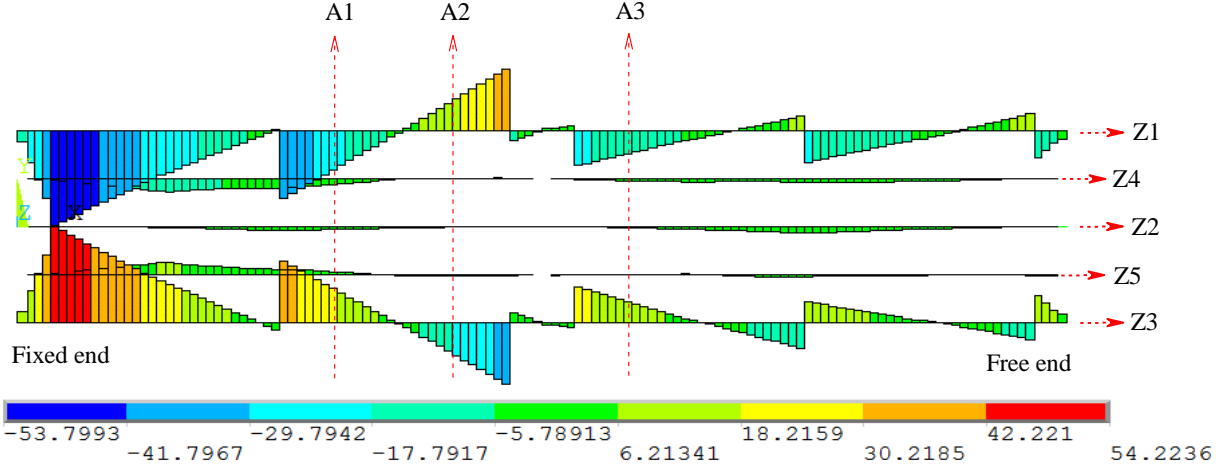

Fig. 11. Stress distribution on the longitudinal I beams of the orthotropic deck (MPa).

(a) Measured results; (b) schematic of the stress state. 


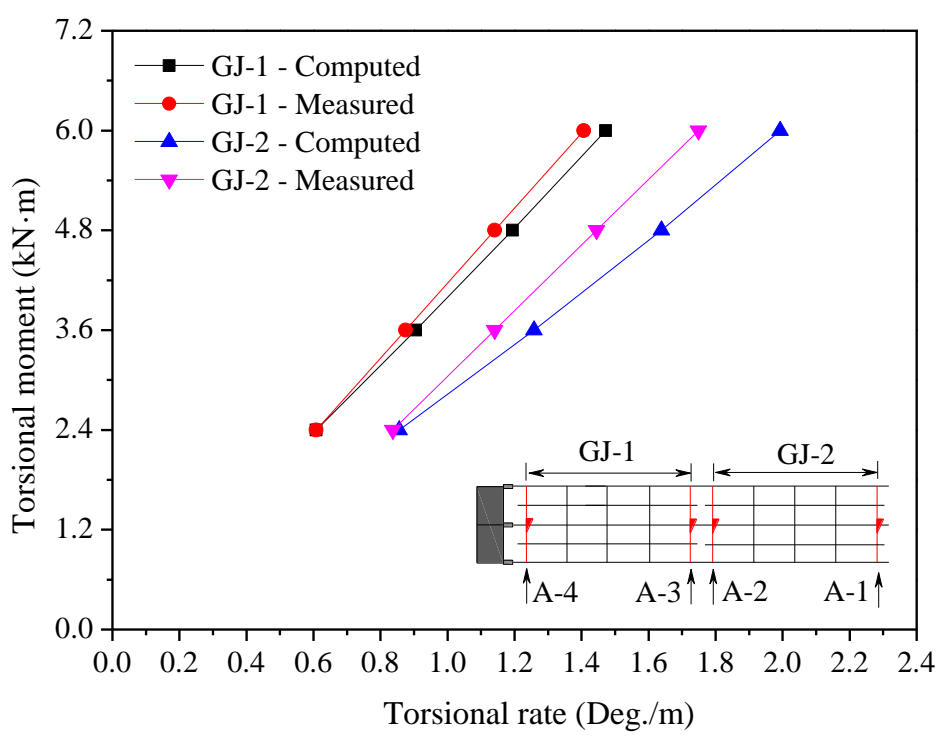

Fig. 12. Comparison of measured and numerical torsional stiffness for the specimen. 
(a)

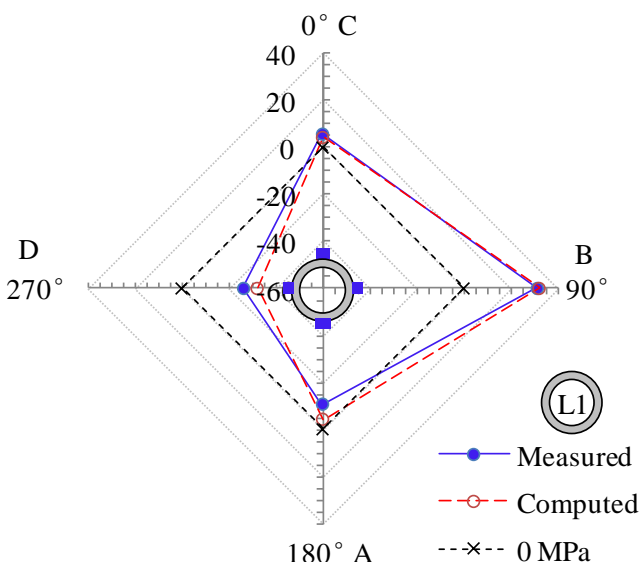

$180^{\circ} \mathrm{A} \quad---x-\cdots 0 \mathrm{MPa}$

(b)
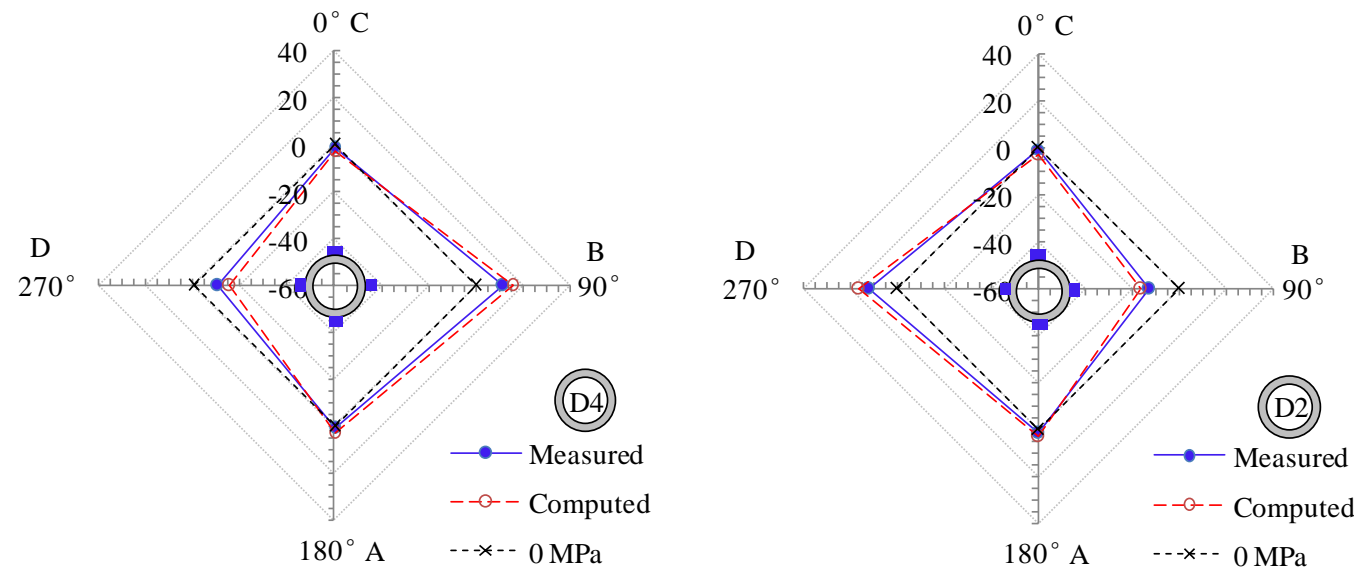

(c)

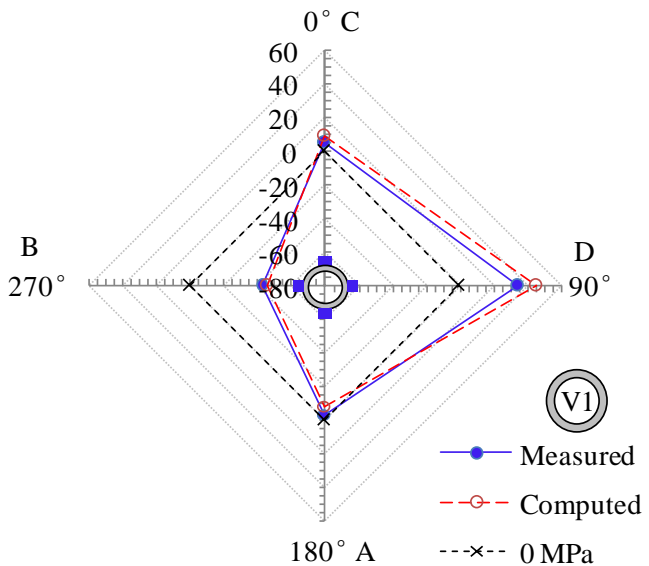

Fig. 13. Comparison of measured and numerical stresses for tubular members (MPa).

(a) Lower chord; (b) web diagonal; (c) vertical. 
(a)

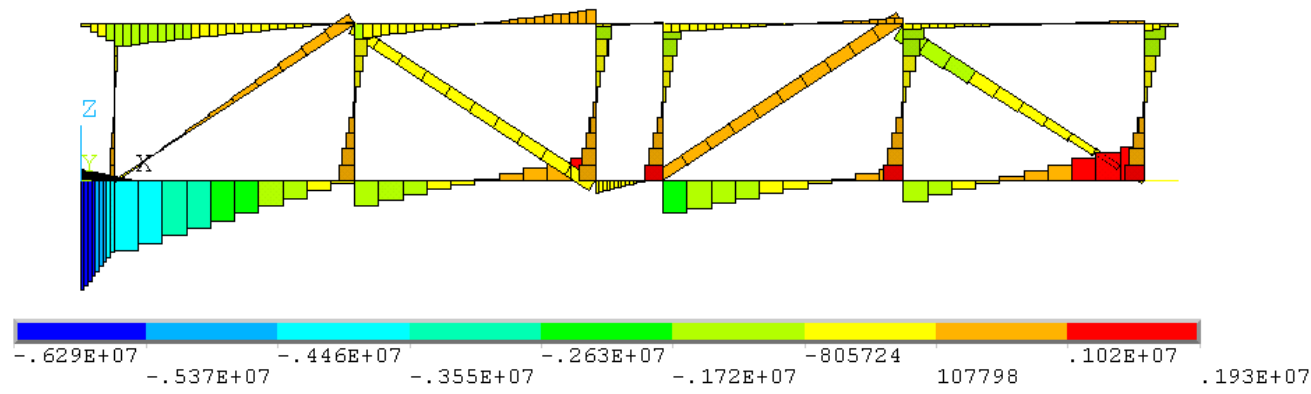

(b)

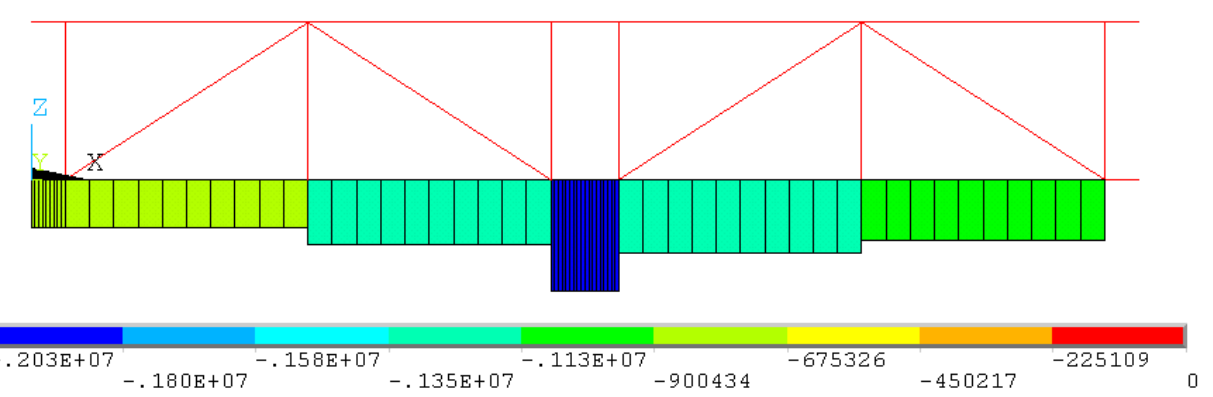

Fig. 14. Internal force contour in the trussed members of M-1 $(\mathrm{N} \cdot \mathrm{mm})$.

(a) Bending moment in the Vierendeel truss; (b) torsional moment in the lower chord. 
(a)
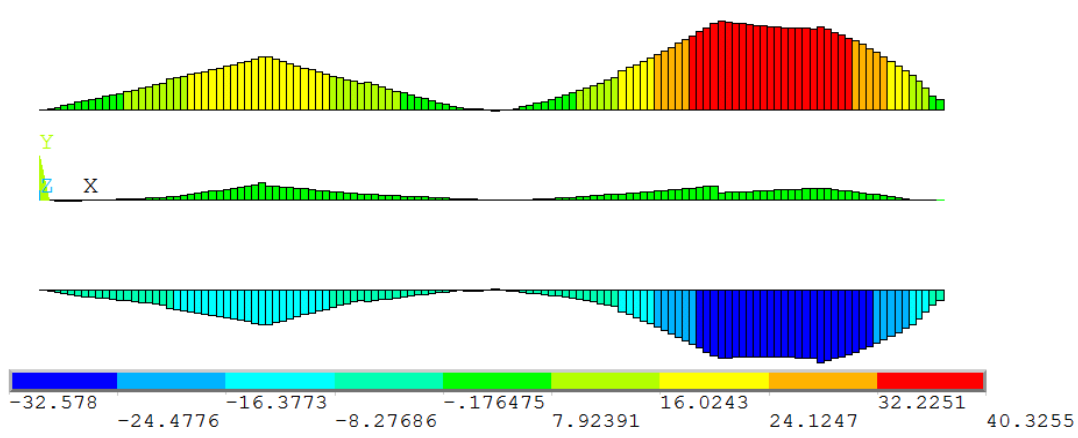

(b)

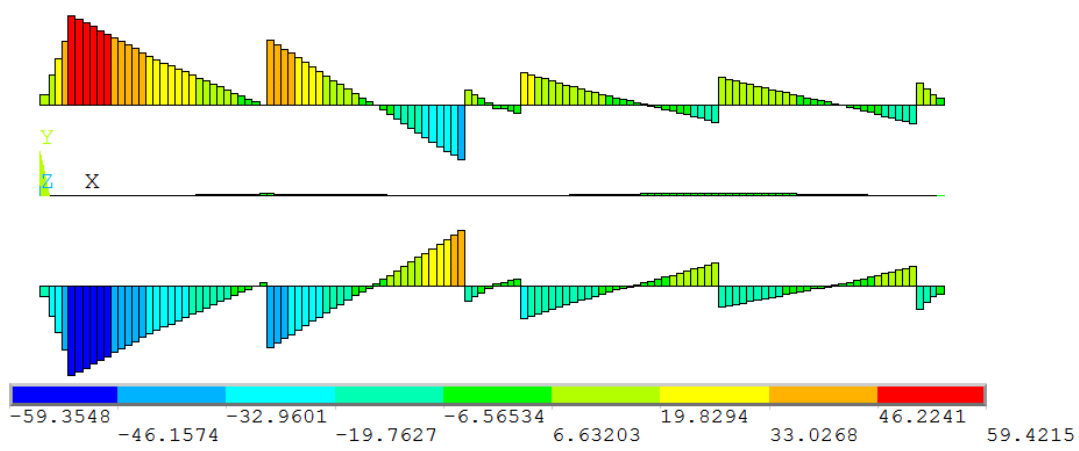

(c)
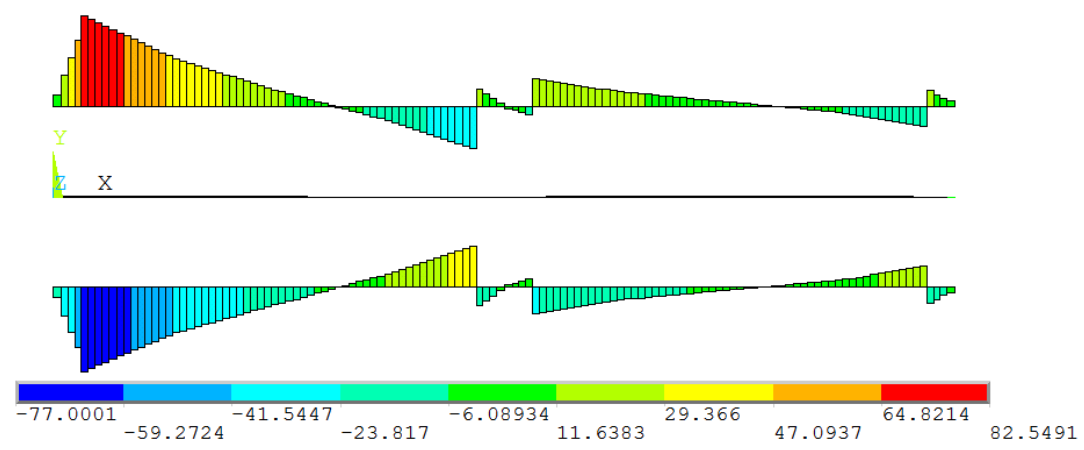

(d)

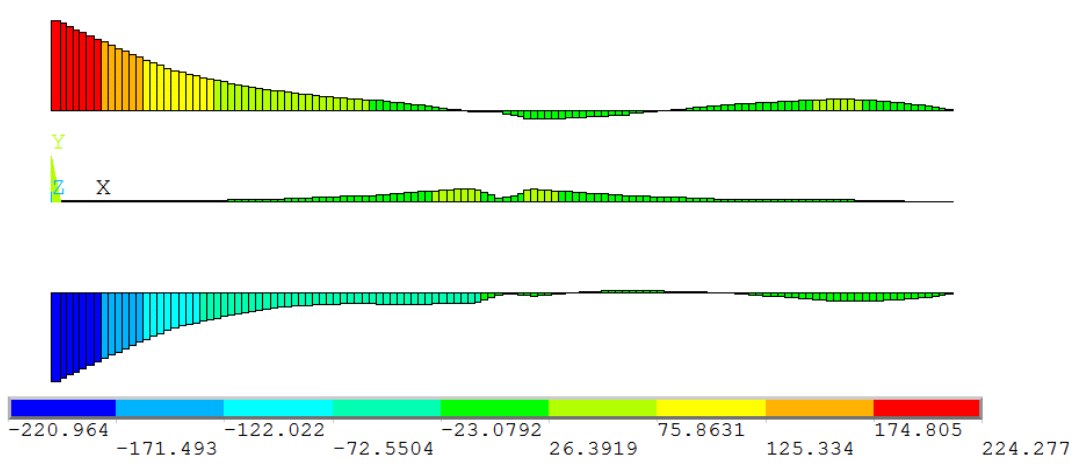

Fig. 15. Bending stress contours in the vertical plane for the main longitudinal I beams (MPa).

(a) M-2; (b) M-3; (c) M-4; (d) M-5. 